\title{
II. Beruflicher und politischer Werdegang vor 1933
}

Beruflicher und politischer Werdegang von Johannes Schauff greifen zeitlich und inhaltlich ineinander, doch soll zuerst auf seine berufliche Option vor dem Hintergrund bäuerlicher Lebensprägung und anschließend auf den genuin politischen Lebensabschnitt in der Weimarer Republik eingegangen werden.

\section{Berufliche Tätigkeit}

\section{Die Gesellschaft zur Förderung der inneren Kolonisation}

Auch Schauffs beruflicher Wechsel zur Gesellschaft zur Förderung der inneren Kolonisation (GFK) am 1. Oktober 1926 kam durch die Vermittlung von Heinrich Brüning zustande ${ }^{1}$. Seine neue Tätigkeit für die ländliche Siedlung vornehmlich im deutschen Osten war der Schritt in einen neuen Lebensabschnitt, auch wenn er durch Interesse und Neigung für diesen Bereich bereits gründlich vorbereitet war. Die bewußte Erfahrung seiner ländlichen Herkunft aus der von der Natur ja keineswegs besonders begünstigten Eifel hatte bereits in der Studienzeit Stoff zu Diskussionen über die „Agrikultur“ geboten - nach Schauffs Auffassung die Grundlage aller Kultur, ein Thema, das er in zahlreichen Zeitungsartikeln über den „Katholizismus und das Landproblem“ zu vertiefen bemüht war ${ }^{2}$. Als Statistikfachmann hatte er ebenfalls in der Presse schon frühzeitig die Kreditlage der Landwirtschaft untersucht ${ }^{3}$.

Schauff analysierte die Verbindung zwischen Katholizität und ländlichem Leben vor allem am Beispiel der ihm vertrauten rheinischen Gebiete. Dort sei das katholische Volksleben vor allem ländlich geprägt, seine Träger seien das Bauerntum und das ländliche Kleinbürgertum. Hier habe der Krieg eine Wende herbeigeführt, eine Erosion des katholischen Milieus insbesondere bei den jungen Menschen bewirkt. In die entstandene Leere dränge zunehmend die völkische Ideologie als „Surrogat für die verlorene Bauernkultur und den mit ihr verlorenen Glauben" ${ }^{4}$. Eine Konsequenz daraus sei die Landflucht und Verstädterung mit

1 Brief Karin Schauff an Heinrich Brüning vom 5. März 1948, in dem sie für Brünings Unterstützung beim Start ihres Mannes ins Berufsleben dankt (vgl. S. 20, Anm. 13).

2 Vgl. Rhein-Mainische Volkszeitung, 28./29. Juli 1924 („Der Katholizismus und das Landproblem“); Rheinisches Zentrum. Mitteilungen der Rheinischen Zentrumspartei, Nr. 11/ 12, November/Dezember 1925, Nr. 1, April 1926 sowie Nr. 2, Juli 1926 („Wo steht unsere Landjugend?"); Das neue Ufer, 20. März 1926 („Das Landproblem des deutschen Westens").

3 Vgl. u.a. Germania, 14. Juli 1926 und 25. August 1926; Kölnische Volkszeitung, 20. Juni 1926 und 24. August 1926.

4 Schauff, Der Katholizismus und das Landproblem. 
allen Gefahren der sozialen Entwurzelung. Als Gegenstrategie schlug Schauff eine "Bauernhochschulbewegung" nach dänischem Beispiel vor, wie sie Karin Schauff kennengelernt und studiert hatte ${ }^{5}$; sie könne der Regeneration bäuerlicher Kultur und christlicher Lebensweise dienen. Träger dieser Bewegung sollte die Landjugend sein, konkret die Jugendorganisation des Reichslandbundes 6 .

Die exemplarische Beschäftigung mit der Entwicklung bäuerlichen Lebens in den katholischen Gebieten Westdeutschlands trübte jedoch keineswegs Schauffs Blick nach Osten, wo ähnliche ländliche Strukturprobleme bestanden, zumal er unterdessen Studium und berufliche Aktivitäten in diesen Raum verlegt hatte. Mehr noch, die Beschäftigung mit der Landjugend auch in Ostdeutschland führte zu konkreter Betrachtung der bäuerlichen West-Ost-Siedlung. Schauff konnte sich bei seinem Eintritt in die GFK vor allem auch auf Heinrich Brünings Überlegungen und Pläne stützen. So hatte Brüning beispielsweise auf der Reichstagung der Windthorstbunde im August 1926 in Soest Grundüberlegungen zur „Siedlungsfrage" entwickelt: Aus Bevölkerungs- und nationalpolitischen Gründen müsse eine starke Bauernsiedlung und Seßhaftmachung von Landarbeitern im deutschen Osten „beschleunigt durchgeführt“ werden; den nachgeborenen Bauernsöhnen solle zur landwirtschaftlichen Selbständigkeit verholfen werden; die Frage der Bereitstellung von Krediten müsse gelöst und damit Mißstände bei den Siedlungsgesellschaften beseitigt sowie eine Überwachung der Siedlungsaktivitäten der Länder und des Reichs gewährleistet werden7. Diese Überlegungen beschreiben auch in wesentlichen Punkten den programmatischen Rahmen der Arbeit der GFK.

Zunächst scheinen jedoch einige Bemerkungen zu Entstehung und bisheriger Entwicklung der GFK notwendig. Sie war vor allem auch eine Reaktion auf die Industrialisierung und die mit ihr einhergehende Abwanderung vom Land in die Städte, die zu einem Nachdrängen polnischer Bevölkerungsteile in die ohnehin bereits von national gemischter Landbevölkerung bewohnten preußischen Provinzen Westpreußen und Posen führte. Die Großgrundbesitzer füllten das entstandene Arbeitskräfte-Defizit mit polnischen Wanderarbeitern, denen gegenüber für sie keine sozialen und rechtlichen Verpflichtungen bestanden. Ihre Verwendung hatte zudem einen ständigen Lohndruck gegenüber den deutschen Landarbeitern zur Folge, die dadurch zunehmend proletarisiert wurden. Die polnischen Wanderarbeiter verstärkten die Gefahr eines Rückgangs des deutschen Bevölkerungsanteils in diesen Provinzen, in denen sich überdies auch der Großgrundbesitz zu einem beträchtlichen Teil in polnischer Hand befand ${ }^{8}$.

5 Vgl. Karin und Johannes Schauff, Volk und Volksbildung.

6 Schauff, Wo steht unsere Landjugend?, S. 39. Der Reichslandbund war der Zusammenschluß des im Kaiserreich gegründeten Bundes der Landwirte mit den während des Ersten Weltkriegs entstandenen Landbünden, eine agrarische Interessenvertretung gegenüber den politisch bestimmenden Kräften in der Weimarer Republik. Vgl. Merkenich, Grüne Front gegen Weimar.

7 Abendblatt der Frankfurter Zeitung, 30. August 1926, S. 4.

8 In der Provinz Posen waren dies 1124000 ha in polnischem gegenüber 1618000 ha. in deutschem Besitz. Vgl. Schwerin, Die Bedeutung der Grundbesitzverteilung, S. 31. 
Angesichts dieser Entwicklung war schon im späten 19. Jahrhundert im Umfeld des „Vereins für Sozialpolitik“, ausgehend von dem Berliner Hochschullehrer und Agrarwissenschaftler Max Sering, die Initiative zu einem parteiübergreifenden Engagement für die „innere Kolonisation“ auf breiterer Basis entstanden, also zu einer koordinierten deutschen Siedlungs- und Volkstumsbewegung in den betroffenen Ostgebieten. Aufgrund historisch-geographischer Gegebenheiten war es vorerst allein Preußen gewesen, das entsprechende Maßnahmen eingeleitet hatte. 1886 wurde das Gesetz über die Beförderung deutscher Ansiedlungen in den Provinzen Westpreußen und Posen erlassen und die Königlich-Preußische Ansiedlungs-Kommission begründet. Die anschließende Gründung und Durchsetzung von gemeinnützigen Siedlungsgesellschaften, z. T. gegen heftige Widerstände aus der Ministerialbürokratie, ist mit dem Namen Friedrich von Schwerin verbunden, Vortragender Rat im Preußischen Innenministerium und dort Referent für die Preußische Ansiedlungs-Kommission.

Schließlich war im Jahr 1912 auf Betreiben von Sering, Schwerin und Erich Keup, einem Agrarfachmann und Schüler Schwerins, die „Gesellschaft zur Förderung der inneren Kolonisation“ (GFK) gegründet worden - mit dem Ziel einer Zusammenführung aller an diesem Unternehmen interessierten Organisationen und gesellschaftlichen Gruppen „unabhängig von allen bürokratischen und allen parteipolitischen Einflüssen"9. Sinn und Zweck waren die ständige Aufklärung über die Notwendigkeit der Siedlung, aber auch die Anleitung zu deren praktischer Durchführung.

All diese staatlichen und privatgesellschaftlichen Aktivitäten hatten bis zum Ersten Weltkrieg nur gedämpfte Resonanz erfahren; zudem hatte sich das Problembewußtsein auf Seiten der Konservativen wie auch der Sozialdemokraten vorerst allein an den großen Gütern orientiert ${ }^{10}$. Erst der Weltkrieg und der Übergang zur Republik führte zu einer grundlegenden Wende. Während des Krieges gab es zahlreiche Bestrebungen, Frontsoldaten Land und Siedlungsmöglichkeiten in Aussicht zu stellen ${ }^{11}$. Um sozialen Unruhen vorzubeugen, aber auch aus Sorge vor Engpässen in der agrarischen Grundversorgung, brachten sozial-konservative Abgeordnete unmittelbar nach Kriegsende einen Reichssiedlungsgesetzentwurf in die Nationalversammlung ein, der am 19. Juli 1919 angenommen wurde und am 11. August in Kraft trat ${ }^{12}$.

Das Gesetz überließ die Durchführung und Finanzierung der Siedlung den Ländern und diente in erster Linie zur Regelung der Landbeschaffung. Vor allem im Osten sollte ein Drittel des Großgrundbesitzes in bäuerlichen Besitz überführt werden. Als organisatorischer Rahmen waren sogenannte Landlieferungsverbände der Eigentümer der großen Güter vorgesehen. Herangezogen werden soll-

9 Boyens, Siedlung, Bd. I, S. 27.

$10 \mathrm{Vgl}$. die im Erfurter Programm der SPD geforderte Beseitigung des „Junkertums“ bei Belassung der Großbetriebe in Staatsbesitz - siehe dazu Kautsky, Die Agrarfrage; zur Haltung der politischen Rechten in der Frage vgl. Boyens, Siedlung, Bd. I, S. 25.

$11 \mathrm{Vgl}$. die Rede Hindenburgs vom 1. Dezember 1918, zit. in Topf, Die grüne Front, S. 269 f.

12 Zur Genesis dieses Gesetzes unter dem Einfluß der GFK und namentlich von Sering und Schwerin vgl. Boyens, Siedlung, Bd. I, S. 30 ff.; der Text des Gesetzes ebenda., S. 44-51. 
ten zunächst Güter, die eine bestimmte Größe überschritten; weitere Kriterien waren schlechte Bewirtschaftung aufgrund ständiger Abwesenheit der Besitzer, häufiger Besitzerwechsel sowie der Erwerb durch Nichtlandwirte während des Krieges. Das Reichssiedlungsgesetz sah als ultima ratio auch Enteignungen vor - bei angemessener Entschädigung der bisherigen Besitzer. Die staatlichen Domänen sollten nach Ablauf der bestehenden Pachtverträge gemeinnützigen Siedlungsunternehmen zum Kauf angeboten werden. Auch unbewirtschaftetes Öd- und Moorland war für eine Enteignung zugunsten von Siedlungen vorgesehen; dies betraf innerhalb der Reichsgrenzen etwa zwei Millionen Hektar Land.

Die Verabschiedung dieses Reichssiedlungsgesetzes führte allerdings nicht zu unmittelbaren Ergebnissen - seine Umsetzung wurde sozusagen „auf Eis“ gelegt: Von seiten des Reichs wurden keine Durchführungsbestimmungen erlassen, die die Länder zum Handeln gezwungen hätten ${ }^{13}$. Mit anderen Worten, das Reich verzichtete auf eine eigene Mitwirkung bei der Umsetzung des Gesetzes. Es gab weder ein zentrales Siedlungsamt ${ }^{14}$ noch wurde die Finanzierung der vorgesehenen Siedlung geregelt. Gleichwohl schufen die Länder durch den Erlaß von Ausführungsgesetzen und den Aufbau von Siedlungsbehörden - den sogenannten Kulturämtern ${ }^{15}$ - sowie durch die Bereitstellung von Krediten erste Grundlagen für eine praktische Siedlungsarbeit.

Die von Sering projektierten 10000 Siedlerstellen per annum erwiesen sich dennoch als Illusion. Dies lag vor allem an dem allgemeinen Kapitalmangel, der von den Ländern auch durch Anleihen nicht behoben werden konnte. Allein Preußen vermochte durch Gründung der Roggenrentenbank größere Summen für die Siedlung bereitzustellen. Neben finanziellen Schwierigkeiten fiel auch die zögerliche Landabgabe des Großgrundbesitzes, verbunden mit einer unzureichenden Resonanz des Siedlungsgedankens im Reich, erschwerend ins Gewicht. In den ersten Nachkriegsjahren siedelten vornehmlich Flüchtlinge aus den verlorengegangenen Ostgebieten, später kamen Siedler vor allem aus dem östlichen Deutschland hinzu. Die gängige Siedlungsform in jenen Jahren war die sogenannte Anliegersiedlung, die in den ersten Nachkriegsjahren vorherrschte ${ }^{16}$.

Ab Mitte der zwanziger Jahre bekam die Siedlungspolitik durch den Aufbau der sogenannten "West-Ost-Siedlung“, d.h. die Einbeziehung von Siedlern aus den westlichen und südlichen Teilen Deutschlands, eine neue Qualität. Dieser Gedanke hatte bis zu diesem Zeitpunkt kaum eine Rolle gespielt. Die Werbung um

13 Preußen erließ am 15. Dezember 1919 ein eigenes "Ausführungsgesetz zum Reichssiedlungsgesetz" (dem die „Ausführungsanweisungen“ I-IV sowie das „Gesetz über die Genehmigung von Siedlungen“ vom 1. März 1923 folgten). Die preußische Gesetzgebung diente auch anderen deutschen Ländern bei der Herausarbeitung von Durchführungsgesetzen als Vorbild. Vgl. Boyens, Siedlung, Bd. I, S. $84 \mathrm{f}$.

14 Lediglich im Reichsarbeitsministerium wurde ein kleines Referat gebildet.

15 Ende 1920 waren in allen deutschen Ländern Siedlungsbehörden enstanden; Preußen hatte eine Landeskulturverwaltung mit 8 Landeskulturämtern und 138 Kulturämtern aufgebaut. Vgl. Boyens, Siedlung, Bd. I, S. 100.

16 Nach dem Reichssiedlungsgesetz konnten Kleinbetriebe durch Landzulage aus Großbesitz aufgewertet werden, jedoch nur bis auf die Größe einer „selbständigen Ackernahrung“, vgl. Boyens, Siedlung, Bd. I, S. $101 \mathrm{ff}$. 
Interessenten wie deren fachkundige Beratung wurden institutionalisiert. Damit eröffnete sich für Johannes Schauff ein ganz neuer beruflicher und politischer Aufgabenbereich.

Vor allem infolge der ungesicherten Finanzierung hatte die Siedlungstätigkeit zu diesem Zeitpunkt einen Tiefstand erreicht; sowohl der Mangel an Siedlern wie auch die Gegnerschaft aus den Reihen des Großgrundbesitzes verstärkten den negativen Trend. Die Formierung einer "West-Ost-Siedlung" war die unmittelbare Reaktion auf diese Entwicklung; ihr Träger sollte in erster Linie das katholische Bauerntum Westdeutschlands sein. Hier galt es, das soziale Problem der „nachgeborenen Bauernsöhne " $\mathrm{zu}$ lösen ${ }^{17}$ und zugleich einen neuen nationalpolitischen Akzent zu setzen.

Als Motor dieser Entwicklung war die „Siedlervermittlungsstelle der Gesellschaft zur Förderung der inneren Kolonisation" vorgesehen, die auf Vorschlag des Direktoriums der provinziellen Siedlungsgesellschaften vom 23. September 1926 eingerichtet wurde ${ }^{18}$ und am 1. Oktober desselben Jahres ihre Arbeit aufnahm; in einem Beirat waren neben der GFK das Reichsarbeitsministerium und die Deutsche Rentenbank-Kreditanstalt vertreten. Die Leitung der Siedlervermittlungsstelle der GFK wurde Silvio Broederich ${ }^{19}$ und Johannes Schauff übertragen.

Boyens, damals selbst Mitarbeiter der GFK, beschreibt Johannes Schauff in seiner neuen Funktion als den „jungen Mann“ inmitten der alten "Siedlungskapitäne“, der sich dort mit „scharfem, schnellen Geist“ behauptet habe ${ }^{20}$. Die Tätigkeit der neuen Vermittlungsstelle hatte sowohl organisatorische wie inhaltliche Aspekte: Es galt einmal, die Tätigkeit der verschiedenen mit Siedlung befaßten Reichsministerien und der einzelnen Siedlungsgesellschaften zu koordinieren. Dies brachte zahlreiche Probleme mit sich, die das Siedlungsverfahren in der Praxis und vor allem die Finanzierung der Projekte betrafen ${ }^{21}$.

Die von Schauff und Broederich erarbeiteten inhaltlichen Vorgaben für eine West-Ost-Siedlungspolitik blieben allerdings nicht unwidersprochen. Bereits auf der ersten Tagung der Siedlervermittlungsstelle im Sitzungssaal der RentenbankKreditanstalt am 21. September 1928 in Berlin warnte Freiherr von Gayl, nach dem Tode Schwerins 1925 Vorsitzender der GFK ${ }^{22}$, angesichts des wachsenden Interesses an der West-Ost-Siedlung - auf der Tagung bestand die Teilnehmerschaft vornehmlich aus Westdeutschen - vor dem Irrglauben, der Osten sei unbeschränkt aufnahmefähig. Schauff dagegen vertrat den Anspruch der Mitgestaltung

17 Vgl. Anton Fehr (Bayerischer Bauernbund, 1920-1933 MdR) in: Archiv für innere Kolonisation, XVIII (1926), S. 338.

18 Archiv für innere Kolonisation, XIX (1927), S. 296 („Die Siedlervermittlungsstelle der Gesellschaft zu Förderung der inneren Kolonisation“).

19 Der Deutsch-Balte Broederich (1870-1952) hatte Theologie studiert und war Gutsbesitzer im Kurländischen; vor und während des Ersten Weltkrieges hatte er zu den bekanntesten Vertretern der deutschen Belange im Baltikum gehört und mußte deshalb nach Kriegsende ins Reich fliehen.

20 Boyens, Siedlung, Bd. I, S. $296 \mathrm{f}$.

21 Vgl. hierzu Schauffs Kommentar in Heft 24 der Schriften zur Förderung der inneren Kolonisation: „Beiträge zur Frage der West-Ostsiedlung“ (1929).

22 Wilhelm Freiherr von Gayl (1879-1945), Direktor Ostpreußische Landgesellschaft, einer der Vertreter Preußens im Reichsrat. Vgl. Boyens, Bd. I, S. V. 
der Ostsiedlung durch den Westen und legte in einem Grundsatzreferat seine Sicht der Tätigkeit der Vermittlungsstelle dar ${ }^{23}$. Seine zentrale Forderung war die Siedlung nach landsmannschaftlichen und konfessionellen Kriterien, die erst eine echte Gemeindebildung ermögliche. Die Siedlungsfrage sei ganz entscheidend eine Siedlerfrage und diese wiederum ein „seelisches“ Problem. Um dem kolonisatorischen Charakter der ländlichen Siedlung wieder mehr Geltung zu verschaffen, sollte man bei der Werbung auch auf sozial schwächere, aber leistungsfähige und anspruchslose Siedler setzen. Schauff trug viel dazu bei, daß eine im Westen wie im Osten gemeinsame Sprachregelung in allen Siedlungsbelangen gesucht wurde. Hierzu wurde auf der Tagung ein gesonderter Ausschuß eingesetzt.

Eine besondere Brisanz besaß Schauffs Forderung nach einer konfessionellen Ausrichtung der Siedlungsbewegung. In Arbeitsteilung kümmerte sich der Protestant Broederich um Siedlungwillige protestantischer Konfession, während Schauff Kontakte zu den Caritasverbänden, den christlichen Gewerkschaften und den katholischen Jugendorganisationen knüpfte. Dabei zeigte sich, daß das evangelische Bauerntum des Westens und Südens für die Ostsiedlung kaum zu erwärmen war; die rheinischen und westfälischen Katholiken hingegen zeigten sich den Siedlungsofferten gegenüber viel offener.

Dies führte dazu, daß die ohnehin bestehenden Konflikte innerhalb von Siedlungspolitikern und Siedlungsträgern zusätzlich eine konfessionelle Dimension erhielten. Protestantisch waren die Gegner des Siedlungsprojektes vor allem in den Reihen des ostdeutschen Großgrundbesitzes. Den Katholiken haftete in der noch frischen Erinnerung des Kulturkampfes das Odium nationaler Unzuverlässigkeit an, und man erblickte in der katholischen Kirche nicht zuletzt auch eine Hauptstütze des polnischen Einflusses östlich der Elbe. Ihr Engagement, im Osten zu siedeln, wurde als ein Versuch Roms gewertet, eine Gegenreformation auf den Weg zu bringen ${ }^{24}$.

Die katholische Seite ließ sich durch solche politisch diffamierenden Anwürfe freilich keineswegs entmutigen, sondern ergriff in der West-Ost-Siedlung sogar die Initiative. In der Öffentlichkeit meldeten sich Männer wie der Jesuit Oswald von Nell-Breuning als Verfechter eines christlich-katholischen Siedlungsgedankens zu Wort ${ }^{25}$, und Schauff rief eine „Auskunfts- und Beratungsstelle beim katholischen Volksverein" in Berlin ins Leben. Ein weiterer und gewichtigerer Schritt war schließlich die auf die Initiative von Johannes Schauff im Jahr 1929 erfolgte Gründung der katholischen Siedlerschule Matgendorf in Mecklenburg; 1930/31 leitete er zudem einen „Katholischen Siedlungsdienst“, dessen Leitung er jedoch nach einer „scharfen Auseinandersetzung" mit Bischof Berning von Osnabrück niederlegte. Schauff warf dem Bischof vor, das Programm einer Ansiedlung

23 Vgl. Archiv für innere Kolonisation, XX (1928), S. $435 \mathrm{ff}$.

24 Vgl. Boyens, Siedlung, Bd. I, S. 308; Fiederlein, Der deutsche Osten, S. 344 ff.

25 „Wenn wir in die letzten Jahre zurückblicken, so können wir sagen: Bismarck hat durch seine Stellungnahme die Katholiken zur Einigung gebracht; der Schulkampf hat ihr weltanschauliches Gewissen wachgerüttelt, und jetzt muß die große Bewegung kommen, die alle vorangegangene Arbeit durch die Erfüllung des christlichen Familienideals krönt. Die Siedlungsarbeit muß aus weltanschaulichem Urgrund hervorgehen“, in: Archiv für innere Kolonisation, XXI [1929], S. 430. 
von Katholiken in Ostdeutschland zu sabotieren, indem er zur Siedlung in der eigenen Diözese aufrief ${ }^{26}$. Hinter einer solcherart konfessionellen Akzentuierung der West-Ost-Siedlung stand zum einen der Gedanke der Milieubewahrung - die Kraft des katholischen Milieus hatte Schauff in seiner rheinischen Heimat selbst positiv erfahren. Sie bildete eine besonders günstige Voraussetzung für katholische Siedlungen im protestantisch geprägten Osten; unübersehbar war aber auch der noch aus dem Kulturkampf herrührende Impetus, „Flagge“ zu zeigen.

Mitte der zwanziger Jahre hatte Karin Schauff als Austauschstudentin die Internationale Volkshochschule in Helsingor in Dänemark sowie die bekanntesten Volkshochschulen des Landes besucht ${ }^{27}$. Die dort entwickelte Schulungsarbeit für die ländliche Bevölkerung mit dem Ziel einer beispielhaften Agrar- und Genossenschaftsorganisation hatte bei Karin und auch bei Johannes Schauff nachhaltigen Eindruck hinterlassen, den sie publizistisch umzusetzen verstanden ${ }^{28}$. Diese Erfahrung, Jungbauern geistig zu schulen und sie damit auf die Siedlungsarbeit vorzubereiten, stand sicherlich bei der Planung und Gründung der Siedlerschule in Matgendorf Pate, die u.a. von dem katholischen Jungmännerverband und ihrem Präses Ludwig Wolker unterstützt wurde. Zielgruppe waren nachgeborene Bauernsöhne vor allem aus dem Westen und Süden Deutschlands, von denen bereits eine Anzahl auf mecklenburgischen Gütern arbeitete. Träger der Schule waren der Caritasverband und der Volksverein für das katholische Deutschland. Das Reichsarbeitsministerium und die mecklenburgische Landgesellschaft unterstützten das Projekt finanziell.

Die Schule von Matgendorf, die von Boyens als Vorposten eigenständigen west- und süddeutschen Bauerntums bei der Wiederbesiedlung der Ostgebiete interpretiert wurde ${ }^{29}$, führte wegen ihres dezidiert katholischen Charakters jedoch sogleich zu Kritik von protestantischer Seite, vor allem von seiten des Evangelischen Siedlungsdienstes. Dieser Dissens konnte jedoch aufgehoben werden, als die protestantische Seite mit der Siedlerschule Diestelow ebenfalls in Mecklenburg eine analoge Einrichtung schuf, die neben die bereits bestehende Volkshochschule Hermannsburg in der Lüneburger Heide trat.

Schauff wie auch Broederich betonten immer wieder die kirchlich-religiöse Grundhaltung der Bauernschaft, die für die Ostsiedlung ein tragendes Element sei. Hatten somit all diese organisatorischen Anstrengungen zur Schulung potentieller Siedler eine ausgesprochen weltanschaulich-religiöse Komponente, so war die Tätigkeit der Siedlervermittlungsstelle gleichwohl sehr pragmatisch orientiert. Dies betraf die bessere Organisation der Umsiedlung: Anstelle des bisherigen schematischen Einzelstellenverkaufs trat eine mehr gruppenbezogene Siedlungs-

26 Vgl. das Schreiben Bischof Kallers zu Schauffs Ausscheiden aus dem Katholischen Siedlungsdienst, 22. August 1931 (IfZ, NL Schauff, Bd. 9); Schreiben Johannes Schauff an Prälat Wosnitza vom 28. Juni 1965 (ebenda).

27 Erstmals 1925/26 und ein zweites Mal - nach Eheschließung mit Johannes Schauff - 1928/ 29, zusammen mit dem ersten Kind (vgl. oben, S. 21 f.).

28 Vgl. Karin und Johannes Schauff, Volk und Volksbildung in Dänemark.

29 Boyens, Siedlung, Bd. I, S. 313. 
methode. Dies betraf aber auch die Vorbereitung in der Heimat und die Zusammenstellung solcher Gruppen an Ort und Stelle ${ }^{30}$.

Dieses praktisch orientierte Vorgehen erwies sich als außerordentlich erfolgreich: Ab 1927 nahm die West-Ost-Siedlung kontinuierlich zu und erreichte mit dem Jahr 1930 einen Höhepunkt. Im Reichsgebiet waren 7441 landwirtschaftliche Siedlungen geschaffen worden, wovon 4551 mehr als 5 Hektar umfaßten. Im Rahmen der West-Ost-Siedlungsaktion waren 852 Familien nach dem Osten gebracht worden; damit entfielen auf sie fast 20 Prozent aller Siedlungsstellen über 5 Hektar ${ }^{31}$.

Die Reichsstelle für Siedlerberatung war unterdessen bemüht, das Bauerntum generell gegenüber der rapide um sich greifenden städtischen Entwicklung aufzuwerten und griff mit diesem gesellschaftlichen Anspruch über den eigentlichen Aufgabenbereich der West-Ost-Siedlungsorganisation hinaus. Ein wichtiges Forum war hierbei die Zeitschrift „Der Ost-Siedler“ unter ihrem Schriftleiter und späteren Herausgeber Johannes Schauff ${ }^{32}$. Als bedeutende Einzelschrift in dieser inhaltlichen Standortbestimmung eines erneuerten und selbstbestimmten Bauerntums erwies sich die ebenfalls von Schauff herausgegebene und wesentlich mitverfaßte Broschüre „Wer kann siedeln?" 33 . Sie arbeitete insbesondere die „seelischen Voraussetzungen“ des siedlungswilligen Bauerntums im Kontrast zum „hedonistischen Leben" in den Städten heraus - die Freude an Familie und Kindern, die Bereitschaft zur Selbsttätigkeit anstelle der Erwartung von Fürsorge, das Vorhandensein von Gemeinschaftsgeist und die Fähigkeit zum Arbeiten in der Gruppe ${ }^{34}$.

Das Jahr 1930 bildete den Höhepunkt der Siedlung im Osten und der Tätigkeit der Siedlervermittlungsstelle. Aus der reinen Vermittlung war eine Beratung und Anleitung der landsuchenden Bauern im Westen geworden, eine Hilfe aber auch für die Siedlungsorganisation im Osten selbst. In der „Reichsstelle für Siedlerberatung", wie die Vermittlungsstelle inzwischen hieß, hatten Broederich und Schauff in wenigen Jahren zwanzig bis dreißig Mitarbeiter um sich gesammelt und geschult, die an den verschiedenen organisatorischen und regionalen Fronten engagierte Arbeit leisteten ${ }^{35}$. Im Hause des "Archivs der inneren Kolonisation“ wurde ein Saal eingerichtet, in dem Schauff regelmäßig zu Tagesfragen der Siedlungspolitik Stellung nahm und zu Fragen und Diskussion zur Verfügung stand. Doch bedeutete dieses erfolgreiche Jahr zugleich eine zunehmende und direktere Einbindung der Tätigkeit der Reichsstelle für Siedlerberatung in die Politik während des nunmehr beginnenden Niedergangs der Weimarer Republik.

$30 \mathrm{Vgl}$. Schauff, Die West-Ost-Siedlung.

31 Zahlen, Tabellen und graphische Darstellung der Wanderungsbewegung bei Schauff, ebenda, sowie Boyens, Siedlung, Bd. I, S. $315 \mathrm{ff}$.

32 Die Zeitschrift erschien 1930-33, Schauff war ab 1930 verantwortlicher Schriftleiter und ab Nr. 10/1931 bis Nr. 4/1933 Schriftleiter und Herausgeber; sein Nachfolger wurde Geert Koch-Weser.

33 Schauff (Hrsg.), Wer kann siedeln? Mitarbeiter an dieser Broschüre waren neben Schauff Wilhelm Boyens, Friedrich Kann, Geert Koch-Weser, Artur von Machui und Karl Maßmann.

34 Schauff, Das Bauerntum, ebenda, S. $28 \mathrm{f}$.

35 Vgl. Erich Keup, Vorwort zu Boyens, Siedlung, Bd. I, S. VII. 


\section{Die Siedlung in der Ära Brüning, Papen und Schleicher}

Während der Regierungszeit Brünings wurde von der Reichsregierung die „Osthilfe“ („Maßnahmen zur Linderung der wirtschaftlichen Not des deutschen Ostens") eingeführt, die fortan in einem politisch befrachteten, dialektischen Spannungsverhältnis zum Gedanken der Ostsiedlung stand. Brüning hatte, wie schon angemerkt, den jungen Schauff der Gesellschaft zur Förderung der inneren Kolonisation vermittelt. Er hatte sich bereits als Abgeordneter mit der Ostsiedlung befaßt, die er vorrangig unter sozial- und bevölkerungspolitischen Aspekten, aber auch unter nationalpolitischen und konfessionellen für bedeutsam hielt ${ }^{36}$. In seiner Regierungserklärung vom 1. April 1930 propagierte Brüning eine „zielbewußte Bauern- und Anliegersiedlung "37, sah aber zugleich die Erhaltung der bestehenden Güter als Priorität an. Für die hiermit intendierte Bewahrung des Status quo sollte die "Osthilfe" den politischen und finanziellen Rahmen bilden.

Hervorgegangen aus der 1928 gegründeten „Ostpreußenhilfe“ hatte die Osthilfe das Ziel, die durch den Weltkrieg und die darauffolgende wirtschaftliche Entwicklung hervorgerufene Agrarkrise, die zudem noch durch die territorialen Veränderungen verschärft wurde, überwinden zu helfen. Das Mittel dazu war die Ent- bzw. Umschuldung der Landwirtschaft, eine Unterstützungsaktion, die zwischen 1929 und 1931 auf das gesamte ostelbische Gebiet ausgedehnt wurde. Am 18. Mai 1929 hatte der Reichstag das Ostpreußenhilfsgesetz verabschiedet ${ }^{38}$; unter der Regierung Brüning setzten großzügige Maßnahmen zur Hilfe für die Ostgebiete ein. So sind im Reichshaushalt 1930 für die Osthilfe rund 122 Millionen Mark ausgewiesen, zu denen noch 10 Millionen aus dem preußischen Haushalt kamen. Für das Jahr 1931 wurden 10 Millionen bereitgestellt, und mit dem Osthilfegesetz vom 31. März 1931 wurde für die weiteren Jahre die enorme Summe von 900 Millionen Mark anvisiert. Dieses Geld sollte in erster Linie der Entschuldung bereits bestehender landwirtschaftlicher Güter dienen, während für die Siedlung und innere Kolonisation vergleichsweise nur Brosamen übrigblieben ${ }^{39}$. Bei der Reichskanzlei wurde eine „Oststelle“ als oberste Dienststelle für die Osthilfe etabliert, deren Aufgaben im Herbst 1931 auf einen Reichskommissar übergingen.

Aus sozial- und nationalpolitischen Gründen besaß das Siedlungsprojekt für Brüning durchaus hohe Bedeutung; er wurde dabei besonders von Arbeitsminister Adam Stegerwald nachdrücklich unterstützt. Eine Reihe von Maßnahmen wie die Gründung der Deutschen Siedlungsbank ${ }^{40}$, an deren Ausstattung in Höhe

36 Vgl. Fiederlein, Der deutsche Osten, S. 285, mit den dort angegebenen Belegstellen; ebenso Archiv für innere Kolonisation, XX (1928), S. 457.

37 Verhandlungen des Reichstags, 4. Wahlperiode, Stenographische Berichte, Bd. 427, 153. Sitzung 2. April 1930, S. 4730.

38 Ostpreußenhilfsgesetz, RGBl. 1929, S. 97/98

39 Nach Erlaß des Osthilfegesetzes vom 31. März 1931 erhielt der Großgrundbesitz bis März 1933 ca. 806 Millionen RM, während auf die kleineren Betriebe 43 Millionen RM entfielen, vgl. RGBl. 1931, S. 117-122 und Sachwörterbuch, Bd. 2, S. 239; Fiederlein, Der deutsche Osten, S. $290 \mathrm{ff}$.; Wengst, Schlange-Schöningen, S. $539 \mathrm{f}$.

40 17. September 1930, der Text des Abkommens in: Seraphim (Hrsg.), Deutsche Siedlungsbank, S. 35-41; Fiederlein, Der deutsche Osten, S. $288 \mathrm{ff}$. 
von 100 Millionen RM sich das Reich und Preußen paritätisch beteiligten, stellen dies unter Beweis. Dennoch hatte der Gedanke der Entschuldung für ihn weiterhin Vorrang vor dem Konzept der Siedlung mit seiner strukturpolitischen bzw. agrarreformerischen Intention.

Schauff und Broederich waren im Verein mit ihrem Team in der GFK-Vermittlungsstelle indes nicht ohne Einfluß auf die zuständigen Gremien der Regierung wie auch auf den Kanzler selbst, der einen Besitzwechsel und die grundsätzliche Änderung der ostdeutschen Agrarstruktur ja keineswegs prinzipiell ablehnte. Schauff wurde vom Siedlungsausschuß des Reichstags als Sachverständiger hinzugezogen und nach Gründung der Siedlungsbank in deren Aufsichtsrat berufen. Ein besonderes Vertrauensverhältnis bestand zu Minister Stegerwald.

Im November 1931 wurde Hans Schlange-Schöningen zum Reichskommissar für die Osthilfe im Range eines Ministers ernannt. Er zog Schauff mit seinem Arbeitskreis zur Beratung und Mitarbeit heran. Schlange-Schöningens Programm lag durchaus auf der Linie der GFK: Überführung der „zusammenbrechenden Großbetriebe in die Nutzungsform der bäuerlichen Familienwirtschaft" sowohl aus ökonomischen wie auch bevölkerungspolitischen Gründen ${ }^{41}$. Zwar vertrat der neue Reichskommissar zunächst und wohl aus taktischen Gründen weiterhin die Erhaltung des Status quo ${ }^{42}$, doch änderte sich die Richtung angesichts der rapide ansteigenden Arbeitslosigkeit mit ihren schwerwiegenden Implikationen im staatlichen und gesellschaftlichen Bereich schon um die Jahreswende 1931/32. Die Verbindung zwischen Arbeitsbeschaffungsmaßnahmen und landwirtschaftlicher Siedlung führte allerdings zu Kompetenzstreitigkeiten zwischen SchlangeSchöningen und dem Reichsarbeitsminister Stegerwald, zwischen denen Schauff als Beauftragter des Reichskanzlers zu vermitteln suchte - allerdings mit der Zielvorgabe, „die Siedlung mit der Osthilfe in der Hand Schlange-Schöningens zu vereinigen "43. Daß es schließlich dazu kam und die Kompetenzen in der Siedlungsfrage auf Schlange-Schöningen übergingen, war nicht zuletzt Ergebnis von Schauffs Bemühungen. Der Kompetenzstreit zwischen dem Osthilfekommissar und Stegerwald hatte jedoch politische Konsequenzen, und das Konfliktszenario innerhalb der Regierung wie auch in Hinblick auf die Opposition erfordert eine genauere Betrachtung.

Schauff berichtet, daß es wie eine Bombe eingeschlagen habe, als Minister Schlange-Schöningen in der Mitgliederversammlung der Gesellschaft zur Förderung der inneren Kolonisation „als Ergänzung zum Sanierungsgesetz der Osthilfe eine großzügige Agrarreform für das Frühjahr ankündigte" 44 . Waren einerseits Osthilfe und Siedlung nur schwer auf einen politischen und wirtschaftlichen Nenner zu bringen, so verbanden sich beim Siedlungprojekt die Ziele einer grundsätzlichen Agrarreform mit dem Zweck von Arbeitsbeschaffungsmaßnahmen.

41 Vgl. Muth, Agrarpolitik, S. 323 f.

42 Muth, Agrarpolitik, S. 326; Wengst, Schlange-Schöningen, S. 239 f.

43 Schauff, Aus meiner beruflichen und politischen Arbeit, S. 3.

44 Es handelte sich um die Tagung der GFK vom 29. Februar 1932; Text der Rede von Schlange-Schöningen in: Archiv für innere Kolonisation, XXIV (1932), S. 79 f.; Schauff, Aus meiner beruflichen und politischen Arbeit, S. $3 \mathrm{f}$. 
Während der Gewerkschafter Stegerwald vorrangig an einer Entlastung des Arbeitsmarktes interessiert war, sah Schlange-Schöningen die Siedlung als Teil eines Agrarreformwerkes im größeren Rahmen einer wirtschaftlichen Stützungspolitik für den deutschen Osten, wobei er dem landwirtschaftlichen Berufsstand allerdings eine herausragende Bedeutung zumaß45.

Neben der Finanzierungsproblematik rief vor allem die Frage der Landbeschaffung in Hinblick auf die nicht entschuldungsfähigen Güter einen schwierigen Kompetenzkonflikt hervor. Hier setzte sich Schlange-Schöningen durch, dem in der Kabinettssitzung des 20. Mai 1932 in einem Verordnungsentwurf die alleinige Kompetenz zugesprochen wurde, nicht entschuldungsfähige Güter „für das Reich freihändig oder im Wege der Zwangsversteigerung zu erwerben"46. Dies war das Kernstück eines Gesetz-Vorentwurfs, an dessen Ausarbeitung Johannes Schauff und Josef Franken als Vertreter der GFK beteiligt waren ${ }^{47}$.

Diese Kompetenzkonflikte und schließlich die Vorbereitungsarbeiten zu einer Siedlungsnotverordnung waren der Öffentlichkeit und insbesondere ostdeutschen grundbesitzenden Familien sowie dem Reichslandbund nicht verborgen geblieben. In der rechtsorientierten Presse wurde das Recht zur Einleitung von Zwangsversteigerungen als bolschewistisches Experiment bezeichnet - eine polemische Apostrophierung, die Schule machen sollte. Zugleich intervenierten einflußreiche Persönlichkeiten aus dem ostelbischen Grundbesitz beim Reichspräsidenten, der mit seinem Anwesen in Neudeck in Westpreußen selbst Gutsbesitzer war. Schauff trug unfreiwillig zur Verschärfung dieser Situation bei, als er aus Pflichtbewußtsein Wilhelm von Gayl, Direktor der Ostpreußischen Landgesellschaft und ehemaliger Präsident der GFK, den dritten vorläufigen Verordnungsentwurf übersandte, den dieser gegenüber Hindenburg als ein „Abgleiten in den Staatssozialismus“" kritisierte ${ }^{48}$. Der Reichspräsident stellte sich auf die Seite der Kritiker: In der Möglichkeit, nicht mehr entschuldungsfähige Grundstücke ohne Antrag der Gläubiger der Zwangsversteigerung zuführen zu können, sah er eine „Enteignung ohne Rechtsgarantie“49.

Dieser Konflikt trug zum Sturz der Regierung Brüning bei, wobei SchlangeSchöningens loyale Haltung gegenüber dem Reichskanzler betont werden muß ${ }^{50}$. Schauff hebt bei diesen Vorgängen die Rolle der konfessionellen Denunziation beim Reichspräsidenten und in der Öffentlichkeit hervor, bei der sich insbesondere der Bruder des amtierenden Außenministers, Freiherr von Neurath, hervorgetan habe ${ }^{51}$. Die Entwicklung traf Schauff schwer, hatten doch er und sein Team

45 Vgl. Fiederlein, Der deutsche Osten, S. 323 ff.; Wengst, Schlange-Schöningen, S. $540 \mathrm{ff}$.

46 Niederschrift der Ministerbesprechung am 20. Mai 1932, BA, R 43 I/1456, abgedruckt in: Akten der Reichskanzlei. Die Kabinette Brüning I und II, Bd. 3, S. 2544-2550; vgl. auch Fiederlein, Der deutsche Osten, S. 340; Wengst, Schlange-Schöningen, S. $544 \mathrm{f}$.

47 Dies vermerkt Johannes Schauff in einem Brief an Oswald von Nell-Breuning vom 6. Dezember 1971, in: IfZ, NL Schauff, Bd. 36.

48 Brief vom 20. Mai 1932, zit. in Braatz, Die agrarisch-industrielle Front, S. 560.

49 Vgl. Wengst, Schlange-Schöningen, S. 545.

50 Vgl. Fiederlein, Der deutsche Osten, S. 376 f. sowie 404 f.; Wengst, Schlange-Schöningen, S. $546 \mathrm{f}$.

51 Schauff, Aus meiner beruflichen und politischen Arbeit, S. 4 f. 
in der Beratungsstelle nach Schlange-Schöningens Ankündigung einer Agrarreform einen Schub zu neuen Aktivitäten erhalten, die ihn und die GFK in der Konfliktphase auch zur Zielscheibe politischer Angriffe machten. Dabei wurde Schauff besonders wegen seiner angeblich einseitigen Interessennahme für die katholischen Siedler aus Westdeutschland angegriffen.

„Mit dem Kabinett Papen fehlte unserer Siedlungsarbeit die Basis der Regierung. Die Siedlungsgegner hatten Trumpf“, vermerkte Schauff ${ }^{52}$. In der Tat fanden nun die agrarpolitischen Gesichtspunkte des Großgrundbesitzes Gehör. Schlange-Schöningens und Brünings Notverordnungsentwurf war nichtig, auf die Siedlung als Mittel sowohl der Agrarreform wie auch der Arbeitsbeschaffung wurde verzichtet. $\mathrm{Zu}$ einer gesetzgeberischen Lösung der anstehenden Probleme kam es unter der Regierung Papen nicht, die sich auf die Verbesserung des Sicherungsschutzes und damit des Osthilfesystems konzentrierte und auf die Siedlung als mögliche Alternative völlig verzichtete ${ }^{53}$. In dieser Phase wendete sich Schauffs Tätigkeit noch stärker ins Politische: Zur Reichstagswahl im Juli 1932 wurde er von der Zentrumspartei als Kandidat für den Wahlkreis Liegnitz nominiert.

\section{Politisches Engagement}

\section{Windthorstbunde und Republikanischer Studentenbund}

Die Kandidatur Schauffs für den Reichstag fiel in eine Zeit, als die Weimarer Republik bereits im Niedergang begriffen war. In seinem Wahlkreis Liegnitz in Niederschlesien, der für das Zentrum ohnehin ein Diasporawahlkreis war, erreichte die NSDAP in den Jahren $1932 / 33$ zuletzt 54 Prozent der Wählerstimmen ${ }^{54}$. Schauff wurde zwar am 31. Juli 1932 über die Reichswahlliste des Zentrums in den Reichstag gewählt, stand jedoch während des Wahlkampfes auf verlorenem Posten.

Im Wahlkreis Liegnitz folgte Schauff als Zentrumskandidat 1932 auf Joseph Wirth. Der ebenfalls niederschlesische Wahlkreis Breslau mit für die Katholiken ähnlich ungünstigen demographischen Bedingungen wurde seit 1924 von Heinrich Brüning gehalten ${ }^{55}$. Die politisch-geographische Nachfolge und Nachbarschaft zu diesen beiden prominenten Zentrumspolitikern und ehemaligen Reichs-

52 Schauff, Aus meiner beruflichen und politischen Arbeit, S. 5.

$53 \mathrm{Vgl}$. Fiederlein, Der deutsche Osten, S. $415 \mathrm{ff}$.

54 Wahlkreis Liegnitz, Reichstagswahlen vom 31. Juli 1932: NSDAP 48\% gegenüber 7,2\% des Zentrums (im Vergleich zum Reichsdurchschnitt: $37,3 \%$ NSDAP und 12,5\% Zentrum); Reichstagswahlen vom 6. November 1932: NSDAP 42,1\% und Zentrum $7,1 \%$ (Reichsdurchschnitt: NSDAP $33,1 \%$ und Zentrum 11,9\%); Reichstagswahlen vom 5. März 1933: NSDAP 54\% gegenüber Zentrum 6,4\% (Reichsdurchschnitt: NSDAP $43,9 \%$ und Zentrum 11,2\%), nach Falter/Lindenberger/Schumann, Wahlen und Abstimmungen, S. $73 \mathrm{ff}$.

55 Wirth war vom September 1930-Juli 1932 Abgeordneter für den Wahlkreis Liegnitz, Brüning vom Mai 1924-Juli 1932 für den Wahlkreis Breslau. 
kanzlern ist weniger Zufall als Hinweis auf beider Rolle und Einfluß auf den jungen Politiker Schauff. Dabei entwickelten sich Einfluß und Bindungen im Falle Wirths vor allem im Umfeld von Schauffs Aktivitäten in der Jugendorganisation des Zentrums, den Windthorstbunden, sowie dem Republikanischen Studentenbund, während die Verbindung zu Brüning in erster Linie mit seiner Arbeit für die innere Siedlung und Kolonisation zusammenhängt.

Doch noch einmal zurück zu den politischen Anfängen. Franz H. Mueller, ein politischer Weggefährte Schauffs seit dessen Jugendtagen, berichtet über das Treffen der Windthorstbunde 1922 in Hildesheim, jener beträchtlichen Schar „bewegter" Jugend mit Wimpeln und Klampfen und in Wandervogel-Kluft, unter denen er Johannes Schauffs kräftige Stimme herauszuhören meint beim Singen jenes Liedes aus dem Bauernkrieg, dessen Refrain lautet: „Spieß voran, drauf und dran, setzt aufs Klosterdach den roten Hahn" 56 .

Muellers launige Erinnerung an die jugendbewegte Zeit darf nicht darüber hinwegtäuschen, daß es den Jungen in der Zentrumspartei mit ihrem politischen Anliegen sehr ernst war. Die Windthorstbunde der Weimarer Republik waren dezidiert republikanisch, ihre politische Galionsfiguren waren die Kanzler Joseph Wirth und Wilhelm Marx, aber auch Zentrumspolitiker wie Joseph Joos und Friedrich Dessauer ${ }^{57}$. Vor allem Wirths Persönlichkeit und Politik besaß wohl für die Zentrumsjugend eine charismatische Ausstrahlung. Dies galt nicht zuletzt für Johannes Schauff, der sich selbst dem „linken Zentrum“ zurechnete, und ein Anhänger sowohl der Reparations- wie Rapallo-Politik von Wirth war. In dieser Phase politischer Sozialisation lernte Schauff auch den offenen Umgang mit Angehörigen der liberalen und der sozialen Demokratie. Während seines Engagements für die Windthorstbunde kristallisierten sich für ihn weiter jene zwei Themenkreise heraus, die für sein berufliches und politisches Leben bestimmend werden sollten: zum einen die Siedlung und Migration vor allem der ländlichen Bevölkerung, zum anderen die Verbesserung republikanischer Strukturen durch eine Änderung des vorherrschenden Wahlrechts ${ }^{58}$.

Parallel zu seinen Aktivitäten in den Windthorstbunden spielte Schauff eine wichtige Rolle bei der Gründung und Führung des „Reichskartells republikanischer Studenten“. Dieses republikanische Studentenkartell war unter dem Eindruck der Ermordung Rathenaus Ende Juli 1922 in Jena aus den Hochschul- bzw. Jugendgruppen der drei Weimarer Koalitionsparteien - SPD, Zentrum und DDP - gebildet worden. Vorausgegangen war die Gründung eines Republikanischen Studentenbundes an der Universität Freiburg, an der Schauffs späterer Schwager Hermann Kopf beteiligt war ${ }^{59}$. Schauff war als Vertreter der Windthorstbunde an der Gründung des Reichskartells beteiligt und leitete später die Gruppen in Berlin und dann in Leipzig. Die Leitung auf Reichsebene bildeten Kopf (Zentrum), Helmuth Preuß (Deutsche Demokratische Partei) und Otto Stammer (SPD), ein stän-

56 Franz H. Mueller/Therese J. Mueller, Vor sechs Jahrzehnten, in: Um der Freiheit willen, S. 1267.

57 Vgl. Schauff, Vom Jungen Zentrum.

58 Hierzu der ebenfalls von S(chauff) gezeichnete Artikel: Jungzentrum.

59 IfZ, NL Schauff, Bd. 9. 
diges Sekretariat wurde in München eingerichtet ${ }^{60}$. Das Kartell verfolgte das politische Ziel des Kampfes "gegen die Reaktion, den Geist der Volksverhetzung und der militaristischen Gewaltpolitik" an den Hochschulen und damit gegen den völkisch-reaktionären Deutschen Hochschulring. Neben den katholischen Jugendund Hochschulgruppen bildete es die einzige halbwegs ernstzunehmende Gegenbewegung gegen die immer radikaler werdenden Völkischen ${ }^{61}$.

Es lag in der Konsequenz ihres politischen Engagements, wenn sich die republikanischen Studenten auch international betätigten. So gründeten sie, als der Weimarer Staat noch kein Mitglied des Völkerbundes war, die „Zentralstelle für studentische Völkerbundsarbeit“. Diese wurde wiederum Mitglied der „Fédération Universitaire Internationale pour la Société des Nations" (FUI), deren Exekutivkomitee Hermann Kopf angehörte. Die FUI organisierte Tagungen und Zusammenkünfte mit Repräsentanten des Völkerbundes in verschiedenen europäischen Hauptstädten. Schauff selbst nahm an einer solchen Tagung 1924 in Genf teil, dem Ort, der später eine wichtige Station in seiner internationalen Tätigkeit sein würde.

In diesen Zusammenhang gehört auch das Engagement der katholischen Studenten in der internationalen Friedensbewegung. So nahm Schauff mit Berliner Kommilitonen und motiviert durch Carl Sonnenschein an dem von Marc Sangnier organisierten dritten Friedens- und Versöhnungskongreß der „Internationale Démocratique pour la Paix" im August 1923 in Freiburg/Breisgau teil62. Dieses Treffen, so berichtet Schauff, habe vor allem zu einer persönlichen Begegnung mit den französischen Teilnehmern geführt ${ }^{63}$.

Schauffs politische Betätigung als Student insbesondere im Rahmen des Republikanischen Studentenbundes schuf Verbindungen, die sein weiteres Leben beeinflussen sollten ${ }^{64}$. Hier sei vor allem auf seine Bekanntschaft mit dem Kreis der „Religiösen Sozialisten“ an der Universität Leipzig hingewiesen. Die religiössoziale Bewegung hatte ihre Wurzeln im 19. Jahrhundert und erstarkte vor allem in der Zeit vor dem Ersten Weltkrieg. Ihre eigentliche, relativ kurze Blütezeit erfuhr sie in der Weimarer Republik. 1919 begann der organisatorische Zusammenschluß verschiedener religiös-sozialer Bewegungen in Deutschland, der 1924 in

60 Ein späteres Mitglied der Reichsleitung war Lichteritz (Pazifist), weitere Aktivisten u.a. Konrad Heiden und der spätere Oberbürgermeister von Frankfurt am Main, Walter Kolb, der Schauff freundschaftlich verbunden war (IfZ, NL Schauff, Bd. 34).

$61 \mathrm{Vgl}$. Schwarz, Studenten in der Weimarer Republik, S. 163.

62 Marc Sangnier (1873-1950) gehörte zu den Wegbereitern einer deutsch-französischen Verständigung nach dem Ersten Weltkrieg; Hauptvertreter der christlich-sozialen Bewegung und der Friedensbewegung in Frankreich, 1921 Gründer der „Internationale Démocratique pour la Paix“, nach 1945 einer der geistigen Väter des „Mouvement Républicain Populaire“ (MRP). Vgl. Riesenberger, Friedensbewegung, S. 1-20.

$63 \mathrm{Vgl}$. Brief Johannes Schauff an Julius Kardinal Döpfner vom 21. November 1973 (IfZ, NL Schauff, Bd. 32). Ein deutscher Exponent der deutsch-französischen Annäherung im Rahmen der katholischen Friedensbewegung war der Mitarbeiter Carl Sonnenscheins und Romanist Hermann Platz, vgl. Riesenberger, Friedensbewegung, S. 2 f.

64 Zum Freundeskreis der Berliner Studienjahre und des Kreises um Carl Sonnenschein gehörten auch Engelbert Dollfuß und Fritz Kühr, beide später Exponenten des ständestaatlichen Regimes in Österreich. 
Merseburg in die "Arbeitsgemeinschaft der religiösen Sozialisten Deutschlands“ mündete und 1926 zum „Bund religiöser Sozialisten Deutschlands“ erweitert wurde mit Gruppierungen wie der „Vereinigung der Freunde für Religion und Völkerfrieden ${ }^{\star 65}$.

Die wichtigste Verbindung bildete zweifelsohne der Hofgeismarer Kreis der Jungsozialisten um Paul Tillich. Waren die Hofgeismarer betont national- und staatsbewußt orientiert, nahmen die "Religiösen Sozialisten" zugleich Elemente der Jugendbewegung vor allem in ihrer antibürgerlichen Ausprägung auf. Hendrik de Man formulierte als gemeinsame Ideenplattform den „Sozialismus als Seelenerlebnis, die Wiederbelebung der religiösen Impulse in der Arbeiterbewegung, die Bildung sozialistischer Menschen als die große Kulturaufgabe von heute ${ }^{\text {"66 }}$ Allerdings waren die Hofgeismarer als Gruppe in der SPD bereits 1926 gescheitert, als Individuen jedoch weiterhin aktiv. Ehemalige Hofgeismarer, der TillichKreis und Hendrik de Man gründeten schließlich zur Jahreswende 1929/30 die Zeitschrift "Neue Blätter für den Sozialismus“ als gemeinsames politisches Forum, eine Initiative, bei der auch der Staatsrechtler Hermann Heller zu nennen ist. In der Führung des „Bundes religiöser Sozialisten“ sah man inhaltliche Berührungspunkte zwischen marxistischer Gesellschaftsanalyse und christlicher Sozialethik, und auch Tillich und sein Kreis vertraten durchaus ähnliche Auffassungen. Die „Neuen Blätter für den Sozialismus" befaßten sich vor allem mit allgemeinen Fragen der geistigen Orientierung, sozialen Problemen sowie mit dem Zusammenhang von Bildung und Politik.

Der Bruch der großen Koalition im März 1930 und der Beginn der Brüningschen Notverordnungspolitik bedeutete auch für den Kreis um die „Neuen Blätter", der sich zunehmend profilierte, ein zunehmend konkreter werdendes politisches Engagement. Die Frontstellung richtete sich gegen den politischen Immobilismus der Sozialdemokratie, zugleich aber auch gegen linksradikale Kräfte. Die „Neuen Blätter" waren von einer militanten Gegnerschaft gegenüber dem aufkommenden Nationalsozialismus geprägt, während ihr personelles Umfeld innerhalb der SPD bestrebt war, die Funktionäre nicht nur politisch, sondern auch durch die Formierung von „Kadern" nahezu militärischen Zuschnitts auf den drohenden Umsturz vorzubereiten. Dabei bauten sie bei einem eventuell erforderlichen Widerstand auf Offiziere der Reichswehr, ja sogar auf linke Dissidenten innerhalb der NSDAP. Analoge Gedankengänge und Forderungen sollten sich später auch bei Johannes Schauff finden, dessen Verbindungen zu den „Religiösen Sozialisten“ und damit auch zum weiteren Kreis um die „Neuen Blätter für den Sozialismus" noch aus seiner Leipziger Zeit herrührten.

Schauff sah sich selbst als eine „Ausnahmeerscheinung“ im Kreis der „Religiösen Sozialisten"67. Dies bezog sich wohl vor allem auf seinen Katholizismus, der gleichwohl bei dem jungen Mann aus der Eifel bereits erstaunlich weltoffen und

65 Vgl. Breipohl, Religiöser Sozialismus, S. $13 \mathrm{ff}$.

66 Denkschrift Hendrik de Mans vom 25. März 1926, zit. in: Martiny, Neue Blätter, S. 380.

67 „Als Katholik und Zentrumsmann war ich in diesen Kreisen - jüdisch, evangelisch oder antikirchlich - ein Unikum" (Handschriftl. Notizen Johannes Schauff, IfZ, NL Schauff, Bd. 24). 
vor allem sozial orientiert war. $\mathrm{Zu}$ dieser Offenheit hatte während der Berliner Studienjahre vor allem die Begegnung mit Oswald von Nell-Breuning beigetragen, der die 1931 veröffentlichte Enzyklika Papst Pius XI. „Quadragesimo anno“ mit ihren fundamentalen Aussagen über die berufsständische Ordnung und das Subsidiaritätsprinzip mit entwarf und ein entschiedener Verfechter des katholischen Siedlungsgedankens war ${ }^{68}$.

Auch das gemeinsame Engagement für die Pädagogik verband Schauff mit den "Religiösen Sozialisten“ und dem Kreis um die „Neuen Blätter". So hatte sich Hermann Heller intensiv an der Volksbildungsarbeit in Leipzig beteiligt, und in Hamburg und Berlin setzte man sich für den Ausbau des Zweiten Bildungsweges ein ${ }^{69}$. Hier fanden sich viele Berührungspunkte zum eigenen Engagement in der Volkshochschulbewegung von Johannes und vor allem auch Karin Schauff.

Neben Heller waren Hans Simons ${ }^{70}$, Reinhold Niebuhr ${ }^{71}$, Karl Thieme ${ }^{72}$ und Maria Grollmus ${ }^{73}$ für Johannes Schauff in den späten zwanziger und frühen drei-

68 Siehe oben, S. 28.

69 Vgl. Heller, Gesammelte Schriften, Bd. I, S. 579 ff.; Martiny, Neue Blätter, S. 378. Zur Rolle Hermann Hellers vgl. die Einleitung von Martin Draht und Christoph Müller zu Heller, Gesammelten Schriften, Bd. I, S, IX ff. sowie die dort angegebene Literatur.

70 Hans Simons (1893-1972), preußischer Ministerialbeamter, Mitgl. SPD, 1925-29 Professor und Direktor Deutsche Hochschule für Politik in Berlin, im Kreis um die „Neuen Blätter für den Sozialismus“, ab 1927 kommissarischer Oberpräsident von Stettin und 1930 bis zum sogenannten Preußenschlag 1932 Oberpräsident für Niederschlesien. 1933 Emigration in die USA, u.a. Hochschullehrer, 1950-60 Präsident New School for Social Research. Nach 1945 Tätigkeit für OMGUS, beteiligt an der Vorbereitung des Grundgesetzes der Bundesrepublik Deutschland (BHB I).

71 Reinhold Niebuhr (1892-1971), amerikanischer Theologe deutscher Abstammung, 192860 Professor für christliche Sozialethik am Union Theological Seminary in New York. Radikaler Kritiker des demokratischen Utopismus und Kapitalismus, später jedoch erbitterter Gegner des Kommunismus. Berief im Sommer 1933 Paul Tillich an das Union Theological Seminary (vgl. dazu Radkau, Deutsche Emigration, S. 43 f.).

72 Karl Thieme (1902-1963), Theologe und Historiker, vor 1933 Professor an der Pädagogischen Akademie Elbing, aktiv in Erwachsenenbildung und Volkshochschulbewegung; gehörte zum Hofgeismarer Kreis der Jungsozialisten, Mitglied SPD; 1927 im Vorstand des „Bundes religiöser Sozialisten“. Thieme erhielt 1933 Berufsverbot, war vorübergehend in Schutzhaft und konvertierte wegen der „Gleichschaltung“ der Evangelischen Kirche 1934 zum Katholizismus; 1934-35 war er Mitherausgeber der Zeitschrift "Junge Front/Michael", die sich zu einem Organ des katholischen Jugendwiderstands entwickelte und verboten wurde. Thieme emigrierte 1935 in die Schweiz, gehörte dort zur Gruppe um den Vita-Nova-Verlag, war Mitarbeiter der von Waldemar Gurian und Otto Michael Knab herausgegebenen "Deutschen Briefe" und stand in politischer Verbindung zu Joseph Wirth und Hermann Rauschning. Nach 1945 war er Hochschullehrer in Mainz und ab 1953 Professor und 1954 Direktor des Dolmetscherinstituts Germersheim/Pfalz; ab 1948 Mitherausgeber des „Freiburger Rundbriefs“, setzte er sich besonders für die Verständigung und gegenseitige Akzeptanz von Christen und Juden ein (BHB II; IfZ, NL Thieme und IfZ, NL Schauff).

73 Maria Grollmus fand nach dem Staatsexamen eine Anstellung als Studienassessorin am Lehrerinnenseminar in Offenburg/Baden. Sie lernte dort Joseph Wirth kennen und wurde Mitarbeiterin an der von ihm mitherausgegebenen Wochenschrift Deutsche Republik sowie der Rhein-Mainischen Volkszeitung. 1929 Übertritt zur KPD, die sie bald wieder verließ. Nach der NS-Machtübernahme wurde ihr Elternhaus in Ratibor zu einer Kontaktstelle des politischen Widerstands, sie leistete Fluchthilfe in die Tschechoslowakei und 
Biger Jahren von besonderer Bedeutung. Maria Grollmus spielte in diesem $\mathrm{Zu}$ sammenhang politisch und menschlich vielleicht die bedeutendste Rolle. Schauff hatte die aus Ratibor stammende Sorbin an der Leipziger Universität und im Republikanischen Studentenbund kennengelernt. Sie war Katholikin, hatte sich jedoch, aus der katholischen Jugendbewegung stammend, der Sozialdemokratie angeschlossen und kam später über KPD und KPDO zur Sozialistischen Arbeiterpartei Deutschlands (SAPD). Zu Maria Grollmus, die 1925 in Leipzig das Staatsexamen für das höhere Lehramt ablegte (und dort 1929 auch mit einer Arbeit über Joseph Görres promovierte), fanden Johannes und Karin Schauff eine enge menschliche Beziehung, die sich später bei gegenseitigen Besuchen in Berlin und der Lausitz oder auf gemeinsamen Wanderungen fortsetzte. „Damals [1925]“ - schreibt Schauff - „erschütterte uns der Tod von Friedrich Ebert, und in der Wahl Hindenburgs zum Reichspräsidenten sahen wir das Ende der jungen Republik herannahen"74. Maria Grollmus, die sich unmittelbar nach der NS-Machtübernahme dem Widerstand anschloß, wurde 1934 verhaftet und starb $1944 \mathrm{im}$ Konzentrationslager Ravensbrück: Ihr Schicksal, von dem sie erst nach Rückkehr aus dem Exil erfuhren, war Johannes und Karin Schauff ein Leben lang gegenwärtig ${ }^{75}$.

Im Spannungsfeld zwischen Christentum und Sozialismus ist auch die frühe Bekanntschaft zwischen Schauff und dem späteren KPD-Funktionär Herbert Wehner in Leipzig anzusiedeln, die nach 1945 zu einer tiefen menschlichen Beziehung führen sollte ${ }^{76}$. Hier bestätigen Schauff wie auch der Freund aus Leipziger Tagen, Karl Thieme, die Neugier und letzten Endes vergebliche Suche nach Verbindendem mit jener militanten und schillernden Bewegung der anarchistischen und kommunistischen Linken, die nicht ohne intellektuelle Attraktion gewesen sei und doch zugleich auch die eigenen geistigen Waffen geschärft habe ${ }^{77}$.

\section{Reichstagsmandat und Wablrechtsfrage}

Windthorstbunde und Republikanischer Studentenbund waren für Johannes Schauff wichtige Stationen auf dem Weg zu einem Reichstagsmandat der Zentrumspartei. Nicht minder wichtig als die dort gemachten politischen und organisatorischen Erfahrungen waren aber auch Schauffs bereits erwähnte wissenschaft-

kümmerte sich vor allem mit Unterstützung katholischer Kreise um Inhaftierte und deren Familien. Sie wurde 1934 in Ratibor verhaftet und 1935 vom VGH Berlin wegen „Vorbereitung zum Hochverrat" zu sechs Jahren Zuchthaus verurteilt (vgl.: Widerstand als „Hochverrat“ 1933-1945, Fiche 0046f.); 1940 wurde Maria Grollmus als „politischer Häftling " in das KL Ravensbrück überstellt, wo sie am 6. August 1944 starb. Johannes Schauff bemühte sich später um ihre postume Würdigung durch eine Briefmarke der Bundespost und Bemühungen für eine Biographie, an der Birgit Sack/Sorbisches Institut, Bautzen, arbeitet.

74 IfZ, NL Schauff, Bd. 24.

75 Weitere biographische Materialien in IfZ, NL Schauff, Bd. 24.

76 Wehner war ursprünglich Anarchist und kam erst 1927 zur KPD. Vgl. Soell, Der junge Wehner, sowie Mehringer, Widerstand und Emigration, S. 12-39.

77 Zur Auseinandersetzung mit den Kommunisten innerhalb des Republikanischen Studentenbundes vgl. IfZ, NL Thieme, Bd. 11. 
lich-schriftstellerische Unternehmungen, die seine Partei auf ihn aufmerksam machten. Dies betraf die auf Anraten seiner Freunde Heinrich Vockel und Heinrich Krone sowie mit Unterstützung von Theodor Heuss, damals Reichstagsabgeordneter der DDP, nach Abschluß seines Studiums und während seiner Tätigkeit beim Institut für Konjunkturforschung verfaßte Untersuchung über das Wahlverhalten der deutschen Katholiken im Kaiserreich und der Weimarer Republik. Das Buch erschien 1928 im Verlag J. P. Bachem in Köln ${ }^{78}$ und war nicht nur - so der Untertitel - eine "politisch-statistische Untersuchung der Reichstagswahlen seit 1871 “, sondern darüber hinaus der „Anfang einer Soziologie der Zentrumspartei“"79.

1929 schließlich erschien das von Schauff herausgegebene Sammelwerk „Neues Wahlrecht“, das eine Wahlrechtsdiskussion förderte, die nach den Reichstagswahlen vom 20 . Mai 1928 verstärkt aufgebrochen war ${ }^{80}$. Zwar hatte der Generalsekretär des Zentrums, Vockel, selbst einen parteioffiziösen Wahlreformentwurf ausgearbeitet, der den Parteigliederungen zugesandt und vielfach publiziert wurde ${ }^{81}$. Auf Anfrage Vockels stellte Reichskanzler Müller aber Schauff 1000 Reichsmark zur Publikation der von ihm initiierten Aufsatzsammlung zur Verfügung ${ }^{82}$. Zur gleichen Zeit zirkulierte in den Führungsgremien der Zentrumspartei eine Untersuchung Schauffs mit dem Titel „Wieviel Katholiken gaben bei den Wahlen vom 20. Mai 1928 in den deutschen Großstädten dem Zentrum bzw. der Bayerischen Volkspartei ihre Stimme?", eine Fortführung seiner zuvor veröffentlichten Untersuchung aus dem Jahre 192883. Schauff analysierte in einer Reihe weiterer Artikel den Stimmenrückgang des Zentrums aus dem Jahr 1928 und wies in einer weiteren Denkschrift "Die Schicksalskurve der Zentrumspartei“ auf die Problematik des Übergewichts der Frauenstimmen hin, dem kein entsprechender Zuwachs an (vor allem männlichen) Erstwählern gegenüberstehe ${ }^{84}$.

Zum Verständnis der Diskussion über eine Wahlrechtsreform in der Weimarer Republik, die schon bald nach Einführung des Verhältniswahlrechts 1918/19 begonnen hatte, ist ein kurzer Rückblick auf die Entwicklung des Wahlsystems im Kaiserreich erforderlich. Das Grundprinzip des Bismarckschen Wahlsystems, des Wahlrechts zum Deutschen Reichstag zwischen 1871 und 1918, bestand in der absoluten Mehrheitswahl für Männer in Einzelwahlkreisen ${ }^{85}$. Um bereits im ersten

78 Schauff, Das Wahlverhalten.

79 Vgl. die (ungezeichnete) Rezension in Das Junge Zentrum 6 (1929), S. 27 f.; Morsey, Einleitung zu: Schauff, Wahlverhalten, S. VII, Anm. 1 (mit weiterführenden Rezensionen). Eine kritische Wertung von Schauffs Studie in Hinblick auf Fragen und Methoden der historischen Wahlforschung durch Otto Büsch, Historische Wahlforschung als Zugang zur Geschichte,in: Büsch/Wölk/Wölk (Hrsg.), Wählerbewegung, S. 14.

80 Schauff (Hrsg.), Neues Wahlrecht. Beiträge zur Wahlreform. Weitere Autoren waren: Karl Braunias, Georg Decker, H.G. Erdmannsdörfer, John H. Humphreys, Carlo Mierendorff, Karin Schauff, Richard Schmidt, Adolf Tecklenburg, Heinrich Teipel, Else Ulich-Beil.

81 Vockel, Wahlrechtsreform, S. 73-78; vgl. Plum, Gesellschaftstruktur, S. 130; Schanbacher, Wahlen und Wahlsystem, S. 194.

82 Schanbacher, Wahlen und Wahlsystem, S. 194.

83 Schauff, Wahlverhalten; Schanbacher, Wahlen und Wahlsystem, S. 194.

${ }^{84}$ Vgl. Morsey, Zur Einführung, in: Schauff, Wahlverhalten, S. VIII f.

85 Wahlgesetz für den Reichstag des Norddeutschen Bundes vom 31. Mai 1869 (BGBl 1869, 
Wahlgang gewählt zu werden, mußte ein Bewerber die absolute Mehrheit der gültigen Stimmen erreichen. In Wahlkreisen, in denen dies keinem Kandidaten gelang, fiel die Entscheidung in einer Stichwahl zwischen den beiden Kandidaten mit der höchsten Stimmenzahl aus dem ersten Wahlgang. Die zunehmende Auffächerung des Parteienfeldes und die damit verbundene Zunahme der Zahl der Kandidaten hatten zu einem raschen Anstieg der Stichwahlverfahren geführt, so daß bei den Reichstagswahlen ab den achtziger Jahren (zuletzt 1912) zumeist rund 50 Prozent der Mandatsträger erst im zweiten Wahlgang ermittelt werden konnten. In Konsequenz hatte sich die Praxis der Bündnisse mit anderen Parteien herausgebildet, die vor allem das bürgerliche Lager begünstigte - „Kartell“ von 1887, „Bülow-Block“ von 190786; die Sozialdemokraten, denen solche Bündnismöglichkeiten nicht offenstanden, wurden dadurch massiv benachteiligt.

Deren Chancenungleichheit rührte auch daher, daß trotz einer erhöhten Bevölkerungsfluktuation die Wahlkreiseinteilung nahezu ein halbes Jahrhundert unverändert blieb. Die Beibehaltung der alten Wahlkreise bewirkte, daß zur Erlangung eines SPD-Mandats in den städtischen Wahlkreisen ein Mehrfaches an Stimmen erforderlich war als zur Erlangung eines Mandats in ländlichen Wahlkreisen. Bei der Zuteilung der Reichstagsmandate waren jene zudem mit 29 Prozent überrepräsentiert; hinzu kam, daß mehr als die Hälfte in den ostelbischen Reichsgebieten lag, die sozial und wirtschaftlich durch den Großgrundbesitz geprägt waren ${ }^{87}$. So kam es, daß noch in den Wahlen von 1907 die SPD in 90 Wahlkreisen zur Stichwahl antrat, jedoch nur 14 Mandate gewinnen konnte, obwohl ihre Kandidaten in 73 dieser Wahlkreise im ersten Wahlgang die relative Mehrheit erreicht hatten ${ }^{88}$.

Das Wahlsystem in der für die Reichstagswahlen praktizierten Form begünstigte aber auch regional verankerte Parteien, darunter nationale Minderheiten der Polen, Dänen und Elsaß-Lothringer sowie Parteien mit Schwerpunkt in schwächer besiedelten agrarischen Gebieten wie die Konservativen in den Reichsteilen jenseits der Elbe. Einen Vorteil hatte auch das Zentrum, dessen Hochburgen in den katholischen Regionen West- und Süddeutschlands sowie in Oberschlesien lagen.

In der schon in den letzten beiden Jahrzehnten des 19. Jahrhunderts einsetzenden Diskussion um Wahlreformen bzw. die Einführung der Verhältniswahl traten die sozialdemokratische Seite, aber auch die Liberalen aufgrund ihrer negativen Erfahrungen mit der Mehrheitswahl zunehmend für ein Proporz- bzw. Verhältniswahlrecht ein. In der SPD kam die Diskussion um eine Neugestaltung des Wahlsystems schon Ende der siebziger Jahre in Gang, und nach den für die Sozialdemokraten ungünstig verlaufenen Reichstagswahlen von 1887 wurde die Forderung nach der Verhältniswahl erstmals offen formuliert und nach dem Erfurter Parteitag 1891 im Parteiprogramm festgeschrieben ${ }^{89}$.

861887 waren dies die beiden konservativen Parteien und die Nationalliberalen, 1907 zusätzlich die Linksliberalen. Vgl. Schanbacher, Wahlen und Wahlsystem, S. 25.

87 Vgl. Büsch/Wölk/Wölk, Wählerbewegung, S. $611 \mathrm{f}$.; Schanbacher, Wahlen und Wahlsystem, S. 29.

88 Zahlen und Statistiken bei Schanbacher, Wahlen und Wahlsystem, S. $26 \mathrm{ff}$.

89 Vgl. Schröder, Handbuch, Bd. 1, S. 471. 
Auch die Liberalen hatten aufgrund ihrer spezifischen Benachteiligung schon früh Interesse am Verhältniswahlsystem bekundet ${ }^{90}$. Bei den Linksliberalen befürwortete insbesondere Friedrich Naumann angesichts der für die Partei schlechten Wahlergebnisse ab 1912 den Proporz, obwohl er ihn zuvor noch heftig bekämpft hatte. Die Verhältniswahl wurde während der Auseinandersetzungen der Kriegsjahre zum allgemeinen Parteiprogramm der Liberalen, und als Naumann nach Verabschiedung der Weimarer Verfassung sich neuerlich gegen das Verhältniswahlsystem wandte, blieb er in der Partei isoliert ${ }^{91}$. Das Zentrum und die Konservativen hingegen hielten bis Kriegsende an dem für sie vorteilhaften Mehrheitswahlsystem fest.

Im November 1918 wurde durch den Rat der Volksbeauftragten ein neues Wahlrecht „auf Grund des proportionalen Wahlsystems“ propagiert, das auch für die einzuberufende konstituierende Versammlung gelten sollte ${ }^{92}$. Am 30 . November 1918 wurde die „Verordnung über die Wahlen zur verfassunggebenden deutschen Nationalversammlung "erlassen und die Wahlordnung bekanntgegeben; als Wahltermin wurde der 19. Januar 1919 festgelegt. Wahlsystem und Wahlrecht unterschieden sich jetzt grundlegend von den Regelungen im Kaiserreich. In insgesamt 38 Wahlkreisen wurde die im Verhältnis zur Bevölkerung pro Wahlkreis festgesetzte Zahl von Mandaten nach dem d'Hondtschen Höchstzahlverfahren ${ }^{93}$ auf die Parteien verteilt, die mit sogenannten starren, von den Wählern nicht mehr veränderbaren Listen antraten. Das Wahlrecht wurde auf alle Männer und Frauen ausgedehnt, die das zwanzigste Lebensjahr vollendet hatten. Dieses nach den Grundsätzen der Verhältniswahl gestaltete Übergangssystem erfuhr 1920 noch einige Modifizierungen ${ }^{94}$ : Es gab nun nur noch 35 Wahlkreise, die wiederum zu Wahlkreisverbänden zusammengefaßt wurden. Pro 60000 Stimmen (im Vergleich zu 150000 in der ersten Wahlordnung von 1918) wurde ein Mandat zugeteilt, mögliche Reststimmen wurden in den meistens aus zwei benachbarten Wahlkreisen gebildeten Wahlkreisverbänden und die dann noch verbleibenden Reststimmen auf Reichsebene verrechnet ${ }^{95}$.

Das Reichswahlgesetz war definitiv ausgearbeitet worden, nachdem Erich Koch-Weser am 30. Oktober 1919 Eduard David im Amt des Innenministers abgelöst hatte. Koch-Weser, dessen Schicksal sich nach 1933 im brasilianischen Exil mit dem von Johannes Schauff verbinden sollte, hatte sogleich seine kritische Sicht des neuen Wahlmodus formuliert: „Es ist der große Vorzug des Verhältniswahl-

90 Sowohl National- wie Linksliberale waren unter dem herrschenden Wahlverfahren ohne regionale oder lokale Hochburgen und erhielten im ersten Wahlgang stets weniger Mandate, als ihrem Stimmenverhältnis entsprochen hätte. Vgl. Schanbacher, Wahlen und Wahlsystem, S. $39 \mathrm{f}$.

91 Vgl. Heuss, Friedrich Naumann. Bd. 2, S. 608.

92 RGBl 1918, S. 1304; Schanbacher, Wahlen und Wahlsystem, S. 47 ff.

93 Nach dem d'Hondtschen Höchstzahlverfahren werden die für die einzelnen Wahlvorschläge (Parteien, Listen) abgegebenen Stimmen nacheinander durch 1, 2, 3 etc. geteilt, bis aus den gewonnenen Teilungszahlen so viele Höchstzahlen ausgesondert werden können wie Sitze zu vergeben sind. Jeder Wahlvorschlag erhält so viele Sitze, wie Höchstzahlen auf ihn entfallen.

94 Schanbacher, Wahlen und Wahlsytem, S. $83 \mathrm{ff}$.

95 Vgl. Falter/Lindenberger/Schumann, Wahlen und Abstimmungen, S. 23 f. 
systems, daß es ermöglicht, jede Partei entsprechend ihrer Stärke im Reichstag vertreten zu lassen. Dagegen ist mit der Verhältniswahl unverkennbar die Gefahr verbunden, daß die Persönlichkeit des Abgeordneten in den Hintergrund tritt und die Partei alles wird."96 Eindringlich wies Koch-Weser auch auf die Gefahr der Zersplitterung und Aktionsunfähigkeit der parlamentarischen Mehrheit hin97.

Dennoch schienen die demokratischen Parteien - die sogenannte Weimarer Koalition aus SPD, Zentrum und DDP, die bereits in den Verfassungskämpfen im Interfraktionellen Ausschuß zusammengearbeitet hatten - mit dem neuen Wahlrecht gut zu fahren. Bei den Wahlen zur Nationalversammlung konnten sie mehr als drei Viertel der Wählerstimmen auf sich vereinigen, während die USPD auf der Linken und die DNVP auf der Rechten zusammen nicht einmal 20 Prozent der Stimmen erreichten ${ }^{98}$. Daß es sich um ein „bürgerliches" Parlament handelte und die "Mehrheitssozialdemokraten nicht den erhofften großen Erfolg hatten (von 421 Mandatsträgern gehörten nur 163 der SPD an), führten jene jedoch keineswegs auf das neue Wahlrecht zurück ${ }^{99}$. Dies änderte sich auch nicht, als achtzehn Monate später mit der Wahl zum 1. Reichstag die SPD fast die Hälfte ihrer Wähler verlor und auch Zentrum ${ }^{100}$ und DDP empfindliche Einbußen erlitten. Dagegen gewannen die radikalen Flügelparteien an Boden. Die Weimarer Koalition, die in der Nationalversammlung fast 80 Prozent der Mandate auf sich hatte vereinigen können, blieb deutlich unter der absoluten Mehrheit ${ }^{101}$, ein Verlust der politischen Mitte, der während der gesamten Weimarer Republik nicht mehr ausgeglichen werden konnte.

Die Einführung des „automatischen“ Systems anstelle des d'Hondtschen Verfahrens und der besonderen Reststimmenverwertung bei der Wahl des Reichstags begünstigte die Zersplitterung des Weimarer Parteiensystems weiter ${ }^{102}$. Da

96 Interview in der Württembergischen Zeitung, Nr. 274, 22. November 1919.

97 Schanbacher, Wahlen und Wahlsystem, S. 83 ff.; zum Problem der Zersplitterung s. Falter/Lindenberger/Schumann, Wahlen und Abstimmungen, S. $24 \mathrm{f}$.

98 Ergebnisse und Zahlen bei Falter/Lindenberger/Schumann, Wahlen und Abstimmungen, S. $41 \mathrm{ff}$.

99 Die Hauptursache für das Verfehlen der Mehrheit sahen die Sozialdemokraten in der Aufsplitterung der Arbeiterbewegung und in den vehementen Angriffen der Spartakisten und der USPD, vgl. Müller, Novemberrevolution, S. 207; Schanbacher, Wahlen und Wahlsystem, S. 66.

100 Hinzu kam, daß durch die Abspaltung der Bayerischen Volkspartei für das Zentrum ein weiterer erheblicher Aderlaß an Wählern stattfand.

101205 bzw. mit der Bayerischen Volkspartei 226 Sitze im Reichstag von insgesamt 459. Tabellen bei Falter/Lindenberger/Schumann, Wahlen und Abstimmungen, S. 44.

102 Automatisches System: Für je 60000 Stimmen erhielt eine Partei in den großen Wahlkreisen einen Sitz; mehrere Wahlkreise wurden zu Wahlkreisverbänden zusammengeschlossen, in denen eine Partei wiederum für insgesamt 60000 Stimmen einen Sitz erhalten konnte, falls sie in diesem Kreis mindestens 30000 Stimmen erhalten hatte. Reststimmen wurden auf die Reichsliste übertragen, wo die Parteien wiederum für 60000 Stimmen jeweils einen Sitz bekamen (allerdings nicht mehr Sitze als sie insgesamt in den Wahlkreisen und -verbänden erhalten hatten). Vgl. Hermens, Demokratie oder Anarchie, S. 168 f.; Falter/Lindenberger/Schumann, Wahlen und Abstimmungen, S. 24 f.; Schanbacher, Wahlen und Wahlsystem, S. $217 \mathrm{ff}$. 
keine Sperrklausel, wie später in der Bundesrepublik die Fünfprozent-Hürde, existierte, waren im 5. Reichstag 193015 Parteien bzw. Listenverbindungen vertreten, während es 1919 nur neun waren. Die Tendenz zu extremistischen Randparteien war bereits in der sogenannten Inflationswahl vom Mai 1924 deutlich geworden, bei der die NSDAP erstmals in den Reichstag gelangte. Die Rechte insgesamt konnte dabei ihren Stimmenanteil gegenüber 1920 auf insgesamt 3,4 Millionen steigern, nachdem auch die DNVP sich fast um ein Viertel verbessern konnte. Die KPD dagegen profitierte von der Spaltung der USPD über der Frage des Beitritts zur Kommunistischen Internationale im Oktober 1920. Danach ging die Mehrheit der USPD-Abgeordneten zur KPD über, die ihr durchschnittliches Reichstagswahlergebnis von 2,1 Prozent bis zum Jahre 1922 auf 12,6 Prozent in den Reichstagswahlen von 1924 steigern konnte ${ }^{103}$. Die weitere Entwicklung der Wählerbewegung - bis 1933 und dem Ende der Weimarer Republik wurden die Wähler weitere sechsmal zu den Urnen gerufen - stand zunächst im Zeichen der sogenannten "goldenen“ Zwanziger Jahre wachsender politischer Stabilität und wirtschaftlicher Prosperität, bis ab 1930 unter dem Einfluß von Weltwirtschaftskrise und wachsender Arbeitslosigkeit die zeitweilig zurückgedrängten radikalen Flügelparteien der Rechten und der Linken wieder politischen Auftrieb bekamen. Die Diskussion um das Wahlrecht und dessen Änderung und Reform, die im Zusammenhang mit der parteipolitischen Entwicklung bereits Anfang der zwanziger Jahre eingesetzt hatte, bekam nunmehr ein besonderes Gewicht.

Trotz des allgemeinen Konsenses der demokratischen Parteien über die Einführung der Verhältniswahl hatte es schon bei den Beratungen zum Wahlgesetz kritische Stimmen ${ }^{104}$ gegeben, daß der Proporz die Freiheit des Wählers beeinträchtigen könne. Man sah die Gefahr, daß sich Parteileitungen zwischen Wähler und Abgeordnete drängen und damit jedes persönliche Verhältnis unterbinden könnten ${ }^{105}$. Die bereits früh unter dem Eindruck des Wahlresultats vom 6. Juni 1920 einsetzende Kritik am Wahlsystem war jedoch verfassungsimmanent und hatte allenfalls eine Reform zum Ziel. Im Zentrum der Kritik standen in den frühen Jahren der Weimarer Republik neben der Wahlkreisorganisation die „Unpersönlichkeit der Wahl“ und das „Vordringen der Interessen- und Berufsvertreter und der Wirtschafts- und Splitterparteien “106. Als Hauptursachen der häufigen Koalitionskrisen und der Schwierigkeiten bei Mehrheitsbildungen wurden das automatische Proporzsystem und die Einheitsstimmzettel angesehen, deren Konsequenz die Zunahme von Splitterparteien und Interessengruppen, eine „Atomisierung" des Parteienwesens sei ${ }^{107}$.

$103 \mathrm{Vgl}$. Falter/Lindenberger/Schumann, Wahlen und Abstimmungen, S. $68 \mathrm{f}$.

104 Erich Koch-Weser wurde bereits erwähnt - vgl. S. 43.

105 Vgl. Karin Schauff, Proportionalsystem, in: Schauff, Neues Wahlrecht. Beiträge zur Wahlreform, S. 131.

106 Schauff, Neues Wahlrecht. Beiträge zur Wahlreform, S. 3.

107 Vgl. Mierendorff, Lebendige Demokratie, S. 1402; Hermens, Demokratie oder Anarchie, S. $29 \mathrm{f}$. 
Kernpunkte der Kritik waren somit einmal die Entfremdung zwischen Wählern und Mandatsträgern und zum andern die mangelnde Funktionalität innerhalb des parlamentarischen Systems. Die Reformvorschläge differierten inhaltlich allerdings deutlich. Vorschläge zu einer partiellen und verfassungsimmanenten Änderung des Wahlrechts, die aus den Reihen der Verfassungsparteien gemacht wurden ${ }^{108}$, zielten auf eine Abschaffung der "reaktionären“ durch eine freie Liste ${ }^{109}$. Dem Wähler sollte ein Mitspracherecht bei der Reihenfolge der von den Parteigremien vorgelegten Listen gegeben werden, um dem Mißstand zu begegnen, daß durch das herrschende System der "streng gebundenen Liste" der Wähler „einer kleinen Gruppe von Parteigrößen überantwortet [wird], denen auf Parteidogmen eingeschworene Mittelmäßigkeiten am genehmsten sind"110. Andere Reformvorschläge zielten auf eine Proportionalisierung der Mehrheitswahl oder eine Majorisierung der Verhältniswahl111. Vorschläge mit verfassungsänderndem Charakter, die von einer Reihe zumeist jüngerer Abgeordneter, Publizisten und Wissenschaftler wie z. B. Heinrich Teipel ${ }^{112}$, Ferdinand A. Hermens ${ }^{113}$ und Carlo Mierendorff 114 gemacht wurden, verlangten die Einführung der relativen Mehrheitswahl nach englischem Muster mit dem erhofften Zwang zu einem stabilen Zweiparteiensystem ${ }^{115}$. All diese Vorschläge gingen quer durch die demokratischen Parteien und wurden - häufig von jüngeren Leuten und über die Parteigrenzen hinweg - à titre individuel gemacht. Ganz anders stellten sich die Reformbemühungen um das Reichswahlgesetz in der politischen Praxis, d.h. in den Regierungen und Ministerien dar. Die bis zum Ende der Weimarer Republik auf parlamentarischem Wege durchgesetzten Änderungen bzw. Novellierungen des Reichswahlgesetzes blieben marginal und waren - wie z.B. die Erhöhung des Unterschriftenquorums für die Einreichung von Wahlvorschlägen - lediglich wahltechnische Neuerungen von untergeordneter Bedeutung. Hinzu kam, daß

108 Hier sind u. a. zu nennen Georg Decker, Else Ulich-Beil, Richard Thoma, Heinrich Vokkel, Adolf Tecklenburg, Werner Hans. Vgl. Schanbacher, Wahlen und Wahlsystem, S. 126. Auch Schauff gehörte zu diesem Kreis, worauf noch zurückzukommen sein wird.

109 Schauff, Neues Wahlrecht. Beiträge zur Wahlreform, S. 4.

110 Pohl, Das Reichstagswahlrecht, Bd. 1, S. 394.

111 Vgl. Erdmannsdörfer, Bestandteile und Wirkungen der Wahlgesetz-Reform, in: Schauff, Neues Wahlrecht. Beiträge zur Wahlreform, S. 165; Schanbacher, Wahlen und Wahlsystem, S. $122 \mathrm{ff}$.

112 Teipel war Redakteur des "Reichsdiensts der deutschen Presse“, später Redakteur der von Joseph Wirth u. a. hrsg. Wochenschrift Deutsche Republik; siehe unten, S. 46 f.

$113 \mathrm{Zu}$ Hermens siehe S. $48 \mathrm{f}$.

114 Mierendorff, Mitgl. der SPD, war Pressereferent im Hessischen Innenministerium, 19251928 Sekretär der sozialdemokratischen Reichstagsfraktion. Siehe unten, S. $49 \mathrm{f}$.

115 Vgl. u. a. die Veröffentlichungen von Teipel und Mierendorff in dem von Johannes Schauff herausgegebenen Sammelwerk Neues Wahlrecht. Beiträge zur Wahlreform sowie weitere Veröffentlichungen von Mierendorff im Vorwärts („Gefahren der Verhältniswahl“, Nr. 408/1. September 1930) und den Neuen Blättern für den Sozialismus („Wahlreform, die Losung der jungen Generation“", 1. Januar 1930, S. 342 ff.); Ferdinand A. Hermens, Verfassung und Verhältniswahl, 21. November 1931 (unveröffentlichte Denkschrift, zit. in: Friedrich Schäfer, Zur Frage des Wahlrechts, in: Hermens/Schieder (Hrsg.), Staat, Wirtschaft und Politik, S. 138f.); Schanbacher, Wahlen und Wahlsystem, S. $121 \mathrm{f}$. 
die Bemühungen um eine Neugestaltung des Wahlsystems und eine Neuregelung des Wahlrechts nur von wenigen, oft isolierten Experten der Fraktionen ausgingen ${ }^{116}$. Das auf Anregung von Erich Koch-Weser am 6. März 1924 in Hinblick auf die anstehenden Wahlen novellierte Wahlgesetz sah zur Eindämmung der Parteienzersplitterung die Erhöhung der notwendigen Unterschriften für die Einrichtung einer Wahlliste von 20 auf 500 vor, ohne daß diese Bemühungen den erwünschten Erfolg gezeitigt hätten.

Die Wahlrechtsdiskussion wurde vornehmlich in den Parteien der „Weimarer Koalition" geführt, die das gleiche Anliegen hatten, den Parlamentarismus im Rahmen der Weimarer Republik funktionsfähig zu erhalten. Dabei traten Parteiegoismen häufig zurück. Gleichwohl gelangten diese drei demokratischen Parteien weder gemeinsam noch innerhalb der einzelnen Parteien zu einer unumstrittenen Zielvorstellung für die notwendige Wahlrechtsreform. Doch lohnt es, Unterscheidungen und Differenzierungen zu beachten.

Johannes Schauffs Partei, das Zentrum, hatte sich 1918 ebenfalls für die Einführung der Verhältniswahl stark gemacht, obwohl die Partei im Kaiserreich mit der Mehrheitswahl gut gefahren war. Doch anders als die Sozialdemokraten, für die die Verhältniswahl eine der wichtigsten Errungenschaften der Revolution darstellte, bewertete das Zentrum den neuen Wahlmodus vornehmlich unter dem funktionalen Aspekt eines konstruktiven Zusammenspiels der demokratischen Kräfte im parlamentarischen System. So konnte das Zentrum ohne ideologischen Ballast durchgängig für eine Wahlreform eintreten, auch wenn der innerparteiliche Konsens über den einzuschlagenden Weg nicht immer gegeben war.

Ein früher Verfechter einer Wahlreform mit dem Ziel eines relativen Mehrheitswahlrechts war der bereits erwähnte Heinrich Teipel ${ }^{117}$, der wiederum mit seinem überparteilichen Ansatz, die Zersplitterung des Parteiwesens zu überwinden, völkisch-bündisch orientierten Vorstellungen der Windthorstbunde nahekam. Neben Heinrich Krone, damals Sekretär der Windthorstbunde, war auch Johannes Schauff mit den Vorstellungen Teipels, der zu den Autoren der bereits angeführten Wahlstudie von Johannes Schauff gehörte, vertraut. Aber erst blieb die Wahlreform ein uneingelöster Programmpunkt parteioffizieller Verlautbarungen. Im Januar 1927 war das Kabinett Marx gebildet worden, in dem der Deutschnationale Walter von Keudell den Demokraten Wilhelm Külz im Innenressort ablöste und somit von dieser Seite keine Initiativen zur Wahlreform zu erwarten waren. Die Reichstagsfraktion des Zentrums versuchte daraufhin mit einer Interpellation am 18. Oktober 1927 die Regierung zum Handeln zu bewegen - ein letzten Endes vergeblicher Vorstoß, auch wenn er sich auf politisch realisierbare Forderungen beschränkte ${ }^{118}$.

Nach der Reichstagswahl vom 20. Mai 1928 und der anschließenden Kritik regionaler Parteigliederungen, die vor allem die Wahlkreisgrößen und den Druck

116 Vgl. Wirth, Eine offene Antwort, S. $708 \mathrm{f}$.

117 Teipel, Das Wahlrecht in der Demokratie, in: Schauff, Neues Wahlrecht. Beiträge zur Wahlreform, S. 7-13; Schanbacher, Wahlen und Wahlsystem, S. $190 \mathrm{ff}$.

118 Vgl. Protokolle der Reichstagsfraktion und des Fraktionsvorstands, S. 144; Schanbacher, Wahlen und Wahlsystem, S. 193. 
von Interessenverbänden bei der Listenaufstellung betrafen, kam die Wahlreformdiskussion verstärkt in Gang, führte jedoch weiterhin zu keiner gemeinsamen Linie. In dieser unbefriedigenden Situation ergriff nunmehr Heinrich Vockel als Generalsekretär der Partei die Initiative und verfaßte einen parteioffiziösen Entwurf für eine baldige Wahlreform ${ }^{119}$. In diesem Zusammenhang wurde von Johannes Schauff mit organisatorischer und finanzieller Unterstützung des Generalsekretärs des Zentrums sowie der Reichskanzlei das Sammelwerk „Neues Wahlrecht" herausgegeben: Darin waren die wichtigsten Beiträge zur Wahlgesetzdiskussion zusammengetragen, parteiübergreifend und im Vergleich auch mit dem europäischen Ausland. In dem Buch kommen u. a. mit Heinrich Teipel und Carlo Mierendorff die kompromißlosen Gegner der bestehenden Verhältniswahl zu Wort, allerdings weist der Herausgeber Schauff in der Einleitung darauf hin, daß es sich dabei um Beiträge handelt, die angesichts der verfassungsändernden Mehrheiten bei der bestehenden politischen Konstellation keine aktuelle Bedeutung besäßen ${ }^{120}$.

„Ein verfassungsänderndes Wahlrecht scheidet aus“ - so Schauff kategorisch in einem eigenen Beitrag "Gesichtspunkte zur Wahlreform“121. Er propagierte lediglich eine "kleine Wahlreform“, die sich mit der Einführung der "freien Liste“ begnügte - d.h. der Wähler sollte die Möglichkeit erhalten, die Reihenfolge der Kandidaten auf der Parteiliste selbst zu bestimmen. Verhältniswahl und Wahlkreisgröße sollten jedoch prinzipiell beibehalten werden. Obwohl Vockel den Schauffschen Reformentwurf durch ein vertrauliches Memorandum an den Parteivorstand untermauerte ${ }^{122}$, wurde er von Kritikern der Verhältniswahl als „Scheinreform" gerügt ${ }^{123}$.

Gleichwohl wurde Schauff durch seine Wahlstudie wie seine in der Presse erschienenen Artikel zur Wahlfrage in Parteikreisen bekannt, und sie verschafften ihm auch „in den Parteigremien ein Mitspracherecht“; die Resonanz war seiner eigenen Aussage nach ansonsten jedoch eher dürftigg ${ }^{124}$. Eine besondere Erwähnung verdient der Beitrag von Karin Schauff, in dem sie einen kritischen Überblick über „Die Entwicklung zum Proportionalsystem in Deutschland“ gibt ${ }^{125}$. Karin Schauff, die damals bereits eine vierköpfige Familie zu versorgen hatte und zudem einen Teil ihrer Zeit den sozialen Unternehmungen von Carl Sonnenschein zukommen ließ, hatte sich in kürzester Zeit sowohl mit der Arbeit ihres Mannes im Bereich der Siedlung und der Erwachsenenbildung vertraut gemacht als auch in die schwierige Materie der Wahlgesetzgebung eingearbeitet, wobei sie insbesondere auch entsprechende Entwicklungen im Ausland zum Vergleich heranzog.

119 Siehe oben, S. 40, Anm. 81.

120 Schauff, Neues Wahlrecht. Beiträge zur Wahlreform, S. $3 \mathrm{f}$.

121 Ebenda, S. $200 \mathrm{ff}$.

122 Das Memorandum vom 11. April 1929. Schanbacher, Wahlen und Wahlsystem, S. 195.

123 So z. B. von dem Schriftleiter der "Centrums-Parlaments-Korrespondenz", Franz Fortmann. Schanbacher, Wahlen und Wahlsystem, S. 195.

124 Schauff, Aus meiner beruflichen und politischen Arbeit, S. 2; Morsey, Zur Einführung, in: Das Wahlverhalten, S. VIII f.

125 Schauff, Neues Wahlrecht. Beiträge zur Wahlreform, S. 126-138. 
Diese schon früh sich zeigende Fähigkeit beider Eheleute Schauff, über den deutschen Tellerrand hinauszublicken, sollte sich schon bald als nützlich erweisen.

Fand Schauffs Bestandsaufnahme der Wahlrechtsdiskussion, die er selbst durchaus auch als Anleitung zum Handeln verstand, in der Zentrumspartei und ihrer Reichstagsfraktion nur partielles Interesse, so sah Joseph Wirth, vom 30. März 1930 bis zum 9. Oktober 1931 Reichsinnenminister, bei seinen Bemühungen, die Wahlreform voranzubringen, in Johannes Schauff den geeigneten Assistenten ${ }^{126}$. Aber auch der von Wirth schließlich vorgelegte Reformentwurf erhielt nicht die notwendige Unterstützung der Reichstagsfraktion des Zentrums ${ }^{127}$. Dies lag auch daran, daß Reichskanzler Brüning sich - trotz gegenteiliger Äußerungen vor dem Fraktionsvorstand ${ }^{128}$ - nicht für die weitgehenden Reformabsichten Wirths engagierte. Brüning war der Auffassung, einer Wahlrechtsreform komme beim Versuch einer Überwindung der Wahl- und Parlamentsmisere keine zentrale Bedeutung zu; vielmehr seien die eigentlichen Gründe für die Auflösung des demokratischen Konsenses und den Vormarsch der Radikalen die Verarmung des Mittelstandes und die Folgen des Versailler Vertrages ${ }^{129}$.

Schauff hatte, wie schon angeführt, Wirth im Innenministerium einige Wochen bei der Ausarbeitung eines neuen Wahlrechts-Entwurfs zugearbeitet. Später, bereits in Vorbereitung auf die Emigration, notierte er über diese Erfahrung: „Hier konnte ich einen Einblick tun, wie sowohl seitens des Ministers, der von der Bedeutung der Wahlrechts-Frage als solcher durchdrungen und ein erklärter Anhänger des englischen Wahlrechts war, als auch von Seiten des Referenten Dr. Kaisenberg ${ }^{130}$, der alle Wahlrechtsverschlechterungen seit 1919 verschuldete, die Frage mangelhaft angepackt wurde, so daß es mich nicht wunderte, daß der Entwurf im Kabinett versandete" 131 .

Die Erfahrung des Niedergangs der Republik, der Verfolgung und der Emigration ließ manche Zentrumspolitiker - und auch manche Sozialdemokraten - später in der Verhältniswahl eine der wesentlichen Ursachen für das Scheitern der ersten deutschen Demokratie sehen. Dies gilt vor allem für einen Kreis jüngerer Zentrumsanhänger und -politiker um Johannes Schauff, zu dem auch Ferdinand Hermens gehörte. Dieser bereits angeführte Weggefährte Schauffs aus dem katholischen Westfalen war „im Sommersemester 1928 als Student nach Berlin“ gekommen und hatte sich „von Dr. Johannes Schauff in die Wahldiskussion einspannen“ lassen; Schauffs Untersuchungen und Analysen zur Wahlrechtsfrage bildeten für Hermens eine fruchtbare Grundlage für eigene Arbeiten auf diesem Gebiet, die ihn zu einem der engagiertesten Gegner der Verhältniswahl werden ließen ${ }^{132}$.

126 Schauff, Aus meiner beruflichen und politischen Arbeit, S. 2.

127 Ziel des Entwurfs war eAus meiner beruflichen und politischen Arbeit, s, Elemente der Mehrheitswahl in die Verhältniswahl zu integrieren, übergroße Wahlkreise abzuschaffen und Sperrklauseln gegen Splitterparteien einzuführen. Vgl. Schanbacher, Wahlen und Wahlsystem, S. $143 \mathrm{f}$.

128 Vgl. Protokolle der Reichstagsfrakrion und des Fraktionsvorstands, Nr. 648, S. 506.

129 Brüning, Memoiren 1918-1934. Stuttgart 1970, S. 54 f.

130 Georg Kaisenberg, geb.1883, ab 1920 (Ministerialrat) im Reichsministerium des Innern.

131 Schauff, Aus meiner beruflichen und politischen Arbeit, S. 2.

132 Hermens bewertet Schauffs Buch zur Wahlrechtsfrage als die „ersten verläßlichen Be- 
Schauffs Analysen und Stellungnahmen zum Wahlrecht wurden, wie schon erwähnt, auch in mehreren Zeitungsartikeln, vor allem in dem Zentrumsorgan "Germania“, veröffentlicht. Sie beförderten seine Kontakte zu Persönlichkeiten, „die sich über Verfassungsfragen und die Zukunft von Weimar Gedanken machten, viele davon aus der demokratischen und sozialdemokratischen Partei"133. Schauff selbst führt vor allem Theodor Heuss und Carlo Mierendorff an, letzterer ebenso Mitautor des Sammelbandes „Neues Wahlrecht" wie der ebenfalls schon angeführte Demokrat Hans Gustav Erdmannsdörfer ${ }^{134}$.

Die Vertreter der DDP bzw. der Deutschen Staatspartei hatten seit der ersten Legislaturperiode in und außerhalb des Parlaments immer wieder auf eine Wahlrechtsreform gedrängt mit dem Ziel, der "Persönlichkeit“ im parlamentarischen Leben wieder mehr Entfaltungsmöglichkeiten zu geben. Protagonisten dieser Vorstöße waren neben Erdmannsdörfer insbesondere Theodor Heuss, Karl Pfister, Wilhelm Külz, Anton Erkelenz, Otto Nuschke und Wilhelm Heile. Diese Politiker standen in der Tradition von Friedrich Naumann und Max Weber, die beide das Verhältniswahlrecht abgelehnt hatten. Ihr Engagement stand in zeitlichem Zusammenhang mit den zunehmend gravierenden Stimmenverlusten in den Wahlen 1928 und 1930, deren Gründe die Demokraten vor allem in der versäumten Wahlrechtsreform sahen. Ihre Bemühungen blieben letzten Endes ebenso fruchtlos wie die von Gleichgesinnten in der Zentrumspartei. Schließlich hatte die Deutsche Staatspartei in den Novemberwahlen 1932 mit nur mehr zwei Mandaten ihre parlamentarische Repräsentanz fast völlig eingebüßt ${ }^{135}$.

Auf sozialdemokratischer Seite hatte es selbst ein Carlo Mierendorff schwer, sich in seiner Partei in der Frage der Wahlrechtsdiskussion Gehör oder gar Zustimmung zu verschaffen. Mierendorff hatte in Schauffs Wahlveröffentlichung der Verhältniswahl eine kompromißlose Absage erteilt, jenem Wahlmodus, um den die SPD seit dem Kaiserreich gekämpft hatte und der nach der Revolution als zentrale Errungenschaft gewissermaßen ideologisch unantastbar geworden war. Dabei hätte die SPD nach Schauffs Analyse bei Wahlen unter den veränderten Bedingungen der Weimarer Republik auf der Grundlage des Mehrheitswahlrechts mehr als die absolute Mehrheit der Mandate erreichen können ${ }^{136}$. Doch taucht die Wahlreform weder im Görlitzer (1921) noch im Heidelberger (1925) Parteiprogramm auf, und auch in der Reichsregierung gingen von der SPD keine entsprechenden Impulse aus ${ }^{137}$.

rechnungen über die voraussichtlichen Wirkungen einer Wahlreform“ (Hermens, Sicherung, T. 1, S. 24; das Textzitat ebenda, S. 26; Hermens, Demokratie oder Anarchie; Hermens, Änderung des Wahlrechts, S. 38-60; zur Wahlrechtsfrage in der Bundesrepublik und der Rolle von Schauff und Hermens siehe Kap. IX/1, S. $145 \mathrm{ff}$.

133 Schauff, Autobiographische Notizen.

134 Schriftsteller, bis 1923 Referent in der Presseabteilung der Reichsregierung, wiederholt Reichstags- und Landtagskandidat der DDP.

$135 \mathrm{Vgl}$. Schanbacher, Wahlen und Wahlsystem, S. 197-204.

136 Schauff, Die parteipolitische Struktur Deutschlands, in: Neues Wahlrecht. Beiträge zur Wahlreform, S. 150.

137 Vgl. Schanbacher, Wahlen und Wahlsystem, S. $204 \mathrm{ff}$. 
Erst gegen Ende der Weimarer Republik formierte sich innerhalb der Sozialdemokratie eine Gruppe meist jüngerer Abgeordneter, die angesichts des fortschreitenden Verfalls des demokratischen Parlamentarismus das herrschende Wahlgesetz kritisch unter die Lupe nahmen. Initiator dieses Kreises war Carlo Mierendorff, damals Pressereferent im hessischen Innenministerium, der über Schauff Kontakt zu Nachwuchspolitikern des Zentrums knüpfte. Ein weiterer Fokus war der Kreis um die „Neuen Blätter für den Sozialismus“, zu dem Schauff, wie schon erwähnt, enge Verbindungen besaß. In den „Neuen Blättern“ hatten Mierendorff, Julius Weber, Walter Pahl, Adolf Reichwein, Theodor Haubach, Paul Nevermann, Hans Simons und Hugo Sinzheimer ein Sprachrohr für ihre kritische Argumentation zur Wahl- und Verfassungsreform. Die Erkenntnis, daß die absolute Verhältniswahl in der Praxis der Listenaufstellung zu einer Erstarrung der Parteien führe, fand jedoch keinen Eingang in die offizielle Parteipolitik. Erst durch die Erfahrung des Scheiterns der Republik, der Verfolgung und auch der Emigration wandten sich auch führende Sozialdemokraten vom Proporzsystem $a b$, eine Neuorientierung, auf die noch einzugehen sein wird.

Schauffs Nomination für ein Reichstagsmandat war innerhalb der Zentrumsführung nahezu einmütig erfolgt, „nur Dr. [Andreas] Hermes schoß quer“138. Dabei stellt sich die Frage nach der Motivation und den Hintergründen dieser Nomination. Auch bei beschränkter Resonanz hatten Schauffs Untersuchungen zur Geschichte und Politik des Zentrums seinen Bekanntheitsgrad in der Partei wachsen lassen. Sein Einstieg in die Politik geht aber wohl in erster Linie auf seine Förderung durch Heinrich Brüning zurück ${ }^{139}$. Das Verhältnis zu diesem Mentor, der ihm ja auch die Stellung in der GFK vermittelt hatte, prägte jedoch zugleich eine gewisse Ambivalenz. Schauff nahm dazu in seinen Aufzeichnungen aus dem Jahre 1934 Stellung: „Wenige Monate vor seiner Kanzlerschaft war er [Brüning] Fraktionsführer geworden. Als solcher suchte er einen ständigen Mitarbeiter und Sekretär. Ich sagte in einer persönlichen Verhandlung prinzipiell zu. Dieselben gingen auch weiter, als Dr. Brüning Kanzler geworden [war] und er ebenfalls einen persönlichen Referenten brauchte. Obwohl ich mich auf die Arbeit eingerichtet hatte - eine Beurlaubung und Bezahlung von der Gesellschaft zur Förderung der inneren Kolonisation war möglich - und davon Mitteilung machte, bekam ich nie eine rechte Antwort von ihm. Eine Zeit lang ging er mir deshalb auch aus dem Wege ... Obwohl mich sein Verhalten sehr geärgert hat, hat es meine Gefühle der Hochachtung ihm gegenüber nicht beeinträchtigt." 140

Mag dieser Vorgang vor dem Hintergrund einer generellen Entscheidungsschwäche der Regierung Brüning zu sehen sein ${ }^{141}$, so ist doch offensichtlich, daß der Kanzler mit Schauff gezielt einen jungen, unverbrauchten Politiker fördern

138 Schauff, Aus meiner beruflichen und politischen Arbeit, S. 5.

139 Auf Schauff wird hingewiesen in "Brüning und die katholisch-sozialen Kräfte in der Weimarer Republik“, in: Brüning, Reden und Aufsätze, S. 330-333.

140 Schauff, Aus meiner beruflichen und politischen Arbeit, S. 5.

141 Vgl. Wengst, Schlange-Schöningen, S. 542; Schulz, Zwischen Demokratie und Diktatur, Bd. 3, S. $768 \mathrm{ff}$. 
und ihm die Möglichkeit der Bewährung geben wollte. Dies zeigt sich in seiner Feuerwehrfunktion auf fast aussichtslosem politischem Terrain wie dem niederschlesischen Wahlkreis, wo Schauff nicht nur geographisch als ein politischer Flügelmann agierte. Ein weiterer Grund für die Nominierung war sicherlich Schauffs agrarpolitische Kompetenz, und Schlesien war zudem ein Gebiet der West-Ost-Siedlung.

So ist es nicht verwunderlich, daß Schauff im Wahlkampf die Siedlungsfrage zu einem der zentralen Themen machte. Insgesamt absolvierte er von Juli 1932 bis März 1933 an die 160 Wahlveranstaltungen ${ }^{142}$, wobei die "Annehmlichkeiten, Fahrkarten und Diäten in keinem Vergleich zu den Opfern persönlicher wie auch allgemeiner Art" standen, zumal „einem die Vergeblichkeit des Bemühens immer klarer wurde" ${ }^{\prime 143}$. Unterstützt wurde er in seinem Wahlkampf von politischen Freunden wie Heinrich Krone, Heinrich Lübke, Heinrich Vockel und Heinrich Brauns sowie Freunden aus dem Siedlungsbereich; die gewichtigsten Stützen waren jedoch die ehemaligen Reichskanzler Brüning und Wirth, mit denen Schauff einige Male gemeinsam auftrat. So heißt es in einem Zeitungsbericht über eine Wahlrechtsveranstaltung in Glogau, daß während einer Rede Schauffs Wirth im Saale erschienen sei. „In diesem Augenblick setzte ein so ungeheuer großer Beifallssturm ein, daß Dr. Schauff seine Ausführungen nicht mehr fortsetzen konnte." 144 Über einen vergleichbaren Vorgang, diesmal einen gemeinsamen Auftritt mit Heinrich Brüning, wird anläßlich von dessen Wahlkampfreise durch Schlesien berichtet: In Liegnitz sei Schauff von dem dortigen Zentrumsvorsitzenden Dr. John als Vertreter der jungen Generation bezeichnet worden, der an den rechten Platz gestellt worden sei ${ }^{145}$.

Inhaltliche Schwerpunkte von Schauffs Wahlkampf waren neben der Agrar- und Siedlungsfrage die Auseinandersetzung mit der amtierenden Regierung Papen. Diese sei - so Schauff am 14. Juli 1932 im Wahlkreis Löwenberg - nichts anderes als eine "Kreatur Hitlers“ und fordere vor allem auf landwirtschaftlichem Gebiet Kritik heraus. Schauff beschuldigte die Nationalsozialisten eines inflationären Entschuldungsprogramms und griff ihre Grund- und Boden-Ideologie an, die sie als „Kurpfuscher auf dem Gebiet der Landwirtschaft“" ausweise. Dabei sei die Siedlungsfrage eine „Lebensfrage des Bauerntums“ - eine Sicht, die vor allem Brüning teilte. Dessen Politik sei, „das gesamte deutsche Volk und alle Berufsschichten auf die gewaltige Not des Ostens und der deutschen Landwirtschaft zu lenken, um sie zu Opfern heranzuziehen, die der Landwirtschaft zufließen sollten"146.

Schauff agierte in seinem Wahlkampf als engagierter Parteigänger Brünings. Vorausssetzung für eine Rückkehr zur Regierung - dies der verbreitete Tenor auf den Wahlveranstaltungen, den auch Schauff vertrat - sei die Etablierung einer stabilen, „autoritären“ Demokratie: „Wir wollen nicht, daß einzelne Stände verkauft

142 Die verschiedenen Auftrittsdispositionen in Glogau, Beuthen, Liebau, Hirschberg und anderen Orten in: IfZ, NL Schauff, Bd. 9.

143 Schauff, Aus meiner beruflichen und politischen Arbeit, S. 6.

144 Schlesische Volkszeitung, 7. Juli 1932.

145 Nene Schlesische Nachrichten, 12. Juli 1932.

146 Der Greif, 16. Juli 1932. 
werden. Wir treten ein für autoritäre Demokratie. Wir treten ein für christlichen Staatsaufbau ... “147. An anderer Stelle betonte Schauff noch einmal, „daß wir eine berufsständische Entwicklung brauchen, daß auch die großen kulturellen und weltanschaulichen Verbände und die berufsständischen Vertretungen des Volkes ihr eigenes Leben behalten und ihre Wirksamkeit weiter entfalten müssen" 148 . Als übergeordnete Leitlinie wurde vorgegeben, daß das Zentrum ein „Ordnungsblock der Mitte" werden müsse.

Waren viele der Wahlkampfaussagen auch politisches Getöse und plakativ, so gibt es doch charakteristische Akzente, die sich auf die zurückliegende und wieder anzustrebende Kanzlerschaft von Heinrich Brüning beziehen: Schauff überhöht Brüning einmal zur „Führergestalt“ und erhebt zum anderen die Forderung nach autoritären Strukturen, wobei Schauffs Formulierungen deutlich an ständestaatliche Vorstellungen erinnern. Sie sollten später noch klarere Konturen bekommen, sich nach den Erfahrungen des vergeblichen Versuchs, dem Vordringen der nationalsozialistischen Flut Einhalt zu gebieten, jedoch auch verfestigen.

Als Schauff in der Reichstagswahl am 31. Juli 1932 erstmals gewählt wurde das Zentrum rangierte im Wahlkreis Liegnitz mit 7,2 Prozent der Wählerstimmen an vierter Stelle ${ }^{149}$-, war er mit 30 Jahren der Benjamin seiner Fraktion. „Zu einer eigentlichen Tätigkeit in Fraktion und Reichstag " - so bilanzierte Schauff im Jahre 1934 - „bin ich in den vierzehn Monaten des Mandats nicht gekommen.“ Als Gründe für den Immobilismus des Zentrums meinte er rückblickend zu erkennen, daß die Fraktion „ein undisziplinierter Haufen ohne Führung “ gewesen sei - vor allem durch den immer offensichtlicher werdenden Gegensatz zwischen Brüning und Kaas. Gegenüber den "geschäftigen alten Herren“ fühlte Schauff sich als junger Abgeordneter gewissermaßen überflüssig, und seine Versuche, sich auf agrar- bzw. siedlungspolitischem Gebiete zu profilieren, stießen nur auf geringes Interesse. Dennoch war es nicht zuletzt auch sein parlamentarisches Engagement, das die politische Entwicklung beschleunigte und schließlich zum Sturz der Regierung Schleicher beitrug: Der vor dem Hintergrund dubioser Praktiken bei der Verteilung von Agrarsubventionen („Osthilfe-Skandal“) am 13. Januar 1933 gestellte Zentrums-Antrag über die Durchführung der "Osthilfe“, einer der Anlässe für den Sturz Schleichers ${ }^{150}$, war von Schauff und Schlange-Schöningen vorbereitet worden ${ }^{151}$. Schauff stand wieder an vorderster Stelle an der ihm vertrauten Agrarfront. Kurt von Schleicher, Reichskanzler seit Dezember 1932, war im Prinzip siedlungsfreundlich und hatte an die Brüningsche Politik auf diesem Gebiete angeknüpft. Als Offizier sah er in der Siedlung einen wichtigen Faktor zur Landesverteidigung im Osten, aber auch zur Arbeitsbeschaffung ${ }^{152}$. Dies

147 Schauff auf einer Wahlkampfveranstaltung in Glogau, 5. Juli 1932, Bericht in: Neue Niederschlesische Nachrichten, 8. Juli 1932.

148 Rede in Görlitz, in: Der Greif, 27. Oktober 1932.

$149 \mathrm{Vg}$. Falter/Lindenberger/Schumann, Wahlen und Abstimmungen, S. 73.

150 Vgl. Morsey, Die Deutsche Zentrumspartei, S. $335 \mathrm{ff}$.

$151 \mathrm{Vgl}$. Schauff, Aus meiner beruflichen und politischen Arbeit, S. 6.

152 Rundfunkrede Schleichers vom 26. Juli 1932, zit. nach: Schulthess' Europäischer Geschichtskalender 73/1932, S. 131, sowie Regierungserklärung vom 15 . Dezember 1932 
brachte ihm die Unterstützung des Allgemeinen Deutschen Gewerkschaftsbundes ein, und im Reichstag erfuhr Schauff die Genugtuung, daß seine Fraktion einen acht Punkte umfassenden großen Siedlungsantrag einbrachte ${ }^{153}$. Schleichers Stab hielt enge Verbindung zur GFK, die ihrerseits den Kanzler zur Aufhebung des Sicherungsverfahrens und des Vollstreckungsschutzes für die großen Güter zu bewegen suchte, was mit der Verordnung vom 19. Dezember 1932 auch geschah $^{154}$. Wie bereits unter Brüning, provozierte diese Entwicklung den heftigsten Protest der Ostelbier, die sich aufs neue in ihrer Existenz bedroht sahen. Träger des Protestes war der Reichslandbund, der auf die Unterstützung Hindenburgs bauen konnte 155 . Aufs neue wurden die Vorwürfe des „Marxismus“ und des "Agrarbolschewismus" erhoben. Die Entwicklung eskalierte vor allem durch das Bekanntwerden des „Osthilfe-Skandals“ und seine Behandlung im Reichstag.

War das Anliegen der Siedlungsbewegung die Änderung der bestehenden Agrarstruktur durch Besitzwechsel, bemühten sich vor allem die DNVP unter ihrem Vorsitzenden Alfred Hugenberg und die Landvolkpartei mit dem Schlagwort "Sicherung des Grundbesitzes“ um eine Rettung des ostelbischen Großgrundbesitzes, dessen Vertreter sich selbst neben der Armee als „tragende Säule“ des Staates verstanden ${ }^{156}$.

Gegen diese Position wandten sich nicht nur die Linksparteien, sondern auch das Zentrum und die Nationalsozialisten. Schauff, der in seiner Siedlungsarbeit eine klassenkämpferische Attitüde gegenüber dem Großgrundbesitz immer abgelehnt hatte ${ }^{157}$, gehörte nun innerhalb seiner Partei zu den treibenden Kräften, die sich dagegen wandten, daß „die Osthilfemaßnahmen zum weitaus überwiegenden Teil der Erhaltung von Großgrundbesitz" dienten und das Bauerntum damit benachteiligt werde ${ }^{158}$. Schlimmer noch, die Privilegierung der großen Güter schien korruptes Verhalten geradezu zu provozieren. Hier bot sich für die demokratischen Parteien die Gelegenheit, zum Gegenschlag gegen ihre Verteufelung als "Agrarbolschewisten" auszuholen.

In der Debatte des Haushaltsausschusses am 19. Januar 1933 und den darauffolgenden Sitzungstagen ging es fast ausschließlich um die Frage, inwieweit einzelne Großgrundbesitzer sich unter Mißachtung der gesetzlichen Vorschriften in den Genuß von Osthilfe-Mitteln gebracht oder - vom Standpunkt der sozialen Gerechtigkeit gesehen - zu hohe finanzielle Zuwendungen erhalten hätten. Schauff hatte zu dieser Debatte mit eigenem Material beigetragen und war im Ausschuß persönlich Angriffen der Deutschnationalen gegen die Siedlung entgegenge-

(Akten der Reichskanzlei. Das Kabinett von Schleicher, Dokument Nr. 25, S. 104); Fiederlein, Der deutsche Osten, S. $422 \mathrm{ff}$.

153 Archiv für innere Kolonisation, XXV (1933), S. 33.

154 Betroffen waren die nicht mehr entschuldungsfähigen Güter. Vgl. Boyens, Siedlung, Bd. II, S. 2351 f.; Fiederlein, Der deutsche Osten, S. 427.

155 Vgl. Bert Hoppe, Von Schleicher zu Hitler; Merkenich, Grüne Front gegen Weimar, S. $266 \mathrm{ff}$.

156 Fiederlein, Der deutsche Osten, S. 64, Anm. 4.

157 Schauff, Das Bauerntum, in: Wer kann siedeln?, S. 29; Boyens, Siedlung, Bd. I, S. 297.

158 Das Zentrum 4 (1933), S. 58 (dort auch Zahlenmaterial, bei dessen Zusammenstellung Schauff nach eigenen Angaben behilflich war). 
treten $^{159}$. Es war dies Schauffs letzter parlamentarischer Auftritt. Die OsthilfeDebatte hatte den heftigen Unwillen des Reichspräsidenten erregt, und daß der amtierende Kanzler Schleicher sie nicht hatte unterbinden können oder wollen, brachte auch ihm den Vorwurf des „Agrarbolschewismus“ ein und führte letztlich zu seinem Sturz ${ }^{160}$. Daß das Zentrum nicht nur Mißstände in der Osthilfe anprangerte, sondern zugleich für eine Weiterführung der Siedlung unter einer „angemessenen Berücksichtigung des Klein- und Mittelbauerntums" eintrat, entsprach allerdings weiterhin Schauffs Politik ${ }^{161}$. Während seines dritten und letzten Wahlkampfes zum Reichstag (5. März 1933) standen noch einmal die Siedlung und ihre Behinderung durch die Osthilfe im Mittelpunkt seines Engagements.

\section{Das Ende der Zentrumspartei}

Am 30. Januar 1933 wurde Adolf Hitler mit der Regierungsbildung betraut. Damit war der Endpunkt des Niedergangs der Weimarer Demokratie erreicht, und es begannen die Terrorisierung, das Verbot und die Selbstauflösung der linken und der bürgerlichen Parteien. Über die Gründe des Untergangs des politischen Katholizismus und der Auflösung der traditionsreichen Zentrumspartei in nur wenigen Monaten notierte Johannes Schauff in seinen schon angeführten „Aufzeichnungen" aus dem Jahr 1934:

„Die Fraktionssitzungen sowohl kurz vor und nach dem 30. Januar [1933] und wie auch vor dem ,Tag von Potsdam' vergingen mit Berichten des Parteivorsitzenden Kaas über seine mehr oder minder erfolgreichen Verhandlungen [ mit der NSDAP]. An den Entscheidungen hatte, soweit ich seit meiner Mitgliedschaft in der Fraktion feststellen konnte, außer einer kleinen Gruppe sonst niemand Anteil ... Wir Neulinge empfanden es als unwürdig, wie die Gesamtfraktion mit vagen Ergebnisberichten abgespeist wurde und man dabei durchblicken ließ, daß man ihrer Diskretion nicht mehr sicher und ihr deshalb nicht mehr wert sei. Besonders übertrieben schienen Vorsicht und Zurückhaltung von Brüning. Dabei konnte man nicht die Auffassung haben, als wenn alle Mitglieder aus privilegierten Führerkreisen sachlich und auch menschlich ihren Aufgaben gewachsen waren [wie] z.B. ein Thomas Esser ${ }^{162}$, [Hans] Bell ${ }^{163}$ und selbst Perlitius ${ }^{164}$. Man hatte gehofft, in den schweren Monaten der Entscheidung in eine treu und fest zusammenhaltende, weltanschaulich geschlossene Kampfgemeinschaft hineinzukommen, statt dessen fühlte man sich in einen undisziplinierten, zu Interessengruppen und ehrgeizigen Cliquen und auseinanderfallenden Haufen versetzt. Für das

159 Reichstag, 5. Ausschuß (Reichshaushalt), 1932-33, BA, RD 1/6; Schauff, Aus meiner beruflichen und politischen Arbeit, S. 6; seine Intervention im Ausschuß ebenfalls in: Der Greif, 2. Februar 1933, S. 3.

160 Fiederlein, Der deutsche Osten, S. 450 ff. (mit weiterführender Literatur).

161 Das Zentrum 4 (1933), S. 70.

162 Thomas Esser (1870-1948), MdR 1921-1933, 1933 in Schutzhaft, nach dem 20. Juli 1944 in der sogenannten „Aktion Gewitter" verhaftet und bis Oktober 1944 Lagerhaft.

163 Hans Bell (1868-1949), MdR 1912-1918 und 1919-1933.

164 Ludwig Perlitius (1872-1938), MdR 1924-1933, ab 1929 Vorsitzender der Reichstagsfraktion des Zentrums. 
Neuaufkommende grundsätzlich andere im Nationalsozialismus, für das Totalitär-Dämonische hatte man kaum ein Gespür. Nur in Taktik denkende routinierte Parlamentarier betrachteten ihn wie jede andere Partei, der man ebenso wie 1918 der Sozialdemokratie schon die Giftzähne in Zusammenarbeit ausbrechen würde. Besonders Thomas Esser tat sich auf Grund der Zusammenarbeit mit Göring als Reichstagspräsident und der väterlichen Beratung, die er ihm als solchem angedeihen ließ, besonders hervor. Ich war oft verwundert, in welchem Vertrauensverhältnis Brüning zu diesen zweitklassigen Leuten stand, wenn er auch die Gefahr der Katastrophe sehr deutlich sah und zum Ausdruck brachte. Ich mußte bald einsehen, daß es vergeblich war, mit den wenigen anderen Jungen, wie Hermann Joseph Schmitt ${ }^{165}$, in den „verfahrenen Laden“ eingetreten zu sein. Später sollte ich bei meiner Mitwirkung bei der Liquidation der Zentrumspartei noch mehr einsehen, daß Partei und Fraktion irgendwie reif zum Untergang waren und daß sich deshalb an ihnen ein notwendiges Schicksal vollzog. Besonders schmerzlich war die sich immer mehr aufdrängende, wenn für uns auch nicht konkret zu belegende Tatsache, daß zwischen Parteiführung, d.h. Prälat Kaas ${ }^{166}$ und der Fraktion [mit] Dr. Brüning, der nur sporadisch erschien und die praktische Arbeit durch Dr. Perlitius durchführen ließ, keine Übereinstimmung bestand. Von den Verhandlungen vor und nach dem 30. [31.] Juli hielt er [Brüning] sich vollkommen zurück. Er lehnte jedes Zusammentreffen mit Herrn von Papen, der in diesen Tagen wichtigsten Figur, ab. Man mußte den Eindruck gewinnen, daß er während und nach seiner Kanzlerschaft schwere persönliche Enttäuschungen erlitten hatte, über die er, mehr Mensch als Politiker, nicht hinwegkommen konnte. Deutlich wurde der Bruch bei dem Kampf um das Ermächtigungsgesetz. Er war ausgesprochen dagegen, und bei der Probeabstimmung der Fraktion stimmten 14 Mann mit ihm, ich eingeschlossen, dagegen. Prälat Kaas, der $\mathrm{m}$ [eines] $\mathrm{E}$ [rachtens] sehr ungern die Partei führte und zu ihrer Existenzberechtigung nicht mehr das volle Zutrauen zu haben schien, schien nur darauf auszugehen, die deutschen Katholiken irgendwie in das neue System einzubauen, um dann nach der erfüllten Aufgabe des Liquidators abzutreten. Er wußte der Fraktion die Zustimmung mit überklugen Argumenten schmackhaft zu machen, indem er auf die vielen ihm zugesagten Bindungen und Vorbehalte hinwies.... Er kam mir immer vor wie der kirchliche Diplomat, der Berater des Nuntius, der in der Zentrumspartei das politische Instrument der Kirchenpolitik sah und dabei nicht mit der Methode des Politikers, sondern der des klugen und juristisch geschulten Verhandlungsführers vorging. Für ihn war deshalb die Zentrumspartei weniger ein Bestandteil des deutschen Volkes und mit seinem Schicksal verhaftet, auf einer langen Tradition fußend, sondern er sah sie als Prälat. Somit konnte ihre Aufgabe für ihn nur eine

165 Hermann Joseph Schmitt (1896-1964), MdR März-November 1933, war bis 1939 Generalsekretär der Dachorganisation der katholischen Arbeitervereine, nach 1939 in Verbindung zu katholischen Widerstandskreisen (Alfred Delp, Bernhard Letterhaus, Nikolaus Groß), 1944 verhaftet, Verfahren vor dem Volksgerichtshof, bis Dezember 1944 im KL Dachau; nach 1945 Verbandspräses der Katholischen Arbeiterbewegung, mit Johannes Schauff befreundet (Korr. Schauff - Schmitt in IfZ, NL Schauff, Bd. 7). Zum katholischen Widerstand siehe unten, S. $68 \mathrm{f}$.

166 Ludwig Kaas, MdR 1919-1933, 1928-1933 Parteivorsitzender des Zentrums. 
taktische Frage sein, die die Zeitlage erforderte und die der überzeitlichen Kirche in dem schnellen Frontenwechsel nicht viel bedeutete. Er scheint mir ebenso wenig - unter internationaler und moralischer Sicht - richtig zu handeln wie der persönlich geblendete, mißtrauische $[u n d]$ national voreingenommene Brüning ..." 167

Solche kritischen Wahrnehmungen waren in Anbetracht der Tatsache, daß der Betrachter noch kaum über das Medium zeitlicher Distanz verfügte, erstaunlich klarsichtig und sind von der späteren Forschung weitgehend bestätigt worden ${ }^{168}$. Die von Schauff im Verlauf dieser Entwicklung vollzogene Wandlung zum Anhänger eines "konservativ-autoritären Regierungssystems" 169 lag durchaus in der allgemeinen Entwicklung der Zentrumspartei seit dem Amtsantritt Brünings, charakterisiert durch den mit der Brüningschen Notverordnungspolitik einhergehenden Funktions- und Machtverlust des Parlaments ${ }^{170}$. Angesichts der zunehmend erschwerten Mehrheitsfindung im Zusammenhang mit dem Erstarken des politischen Extremismus von links und von rechts war das Zentrum während Brünings Kanzlerschaft und nach seinem Sturz vorübergehend sogar bereit, mit den Nationalsozialisten zu koalieren ${ }^{171}$.

Dies alles blieb nicht ohne Eindruck auf Johannes Schauff. Auf junge Zentrumspolitiker wie ihn wirkte offensichtlich das Charisma Brünings in besonders starkem Maß. Der Kanzler schien das Symbol einer Zeitenwende. Brünings Wahlkampf-Kritik am überkommenen Parlamentarismus und seinen "Auswüchsen“ und "Übertreibungen“ 172 machten sich vor allem jüngere Zentrumspolitiker zu eigen. Schauffs Kritik am Verhältniswahlrecht - bis dahin relativ zurückhaltend und verfassungskonform - wandelte sich nun zu der Erkenntnis, daß der Proporz eine der wesentlichen Ursachen des Niedergangs des Parlamentarismus und der Weimarer Republik gewesen sei.

Auch Schauffs Kritik an der inneren Struktur des Zentrums vor allem hinsichtlich des Führungspersonals und seiner inneren Querelen zeigt sich im nachhinein als nicht unzutreffend. Rudolf Morsey weist auf die Dominanz der noch im Wilhelminischen Deutschland geprägten Honoratioren einerseits sowie zum andern der "Zentrumsprälaten" in den Spitzenpositionen des politischen Katholizismus hin, darunter auf die in seiner Persönlichkeit begründete problematische Führungsrolle des Parteivorsitzenden Ludwig Kaas. Wie Brüning ein Zauderer und Skeptiker, war Kaas dem Amt nicht zuletzt auch wegen körperlicher Gebrechen nur bedingt gewachsen; auch beobachtete Schauff richtig, daß die Denkwelt von Kaas in juristischen Konstruktionen gefangen blieb und sein vordringlichstes Ziel darin bestand, einen vertragsrechtlichen Ausgleich von kirchlichen und staat-

167 Schauff, Aus meiner beruflichen und politischen Arbeit, S. 6 f.

$168 \mathrm{Vgl}$. vor allem Morsey, Der Untergang. In dieser Studie sind die angeführten Aufzeichnungen Schauffs vom Dezember 1934 berücksichtigt und zitiert (S. 212 Anm. 19).

169 Schauff, Aus meiner beruflichen und politischen Arbeit, S. 3.

170 Vgl. Bracher, Die Auflösung der Weimarer Republik, S. $299 \mathrm{ff}$. Bracher spricht in diesem Zusammenhang von einem „Semiparlamentarismus“ (S. 335); Schulz, Zwischen Demokratie und Diktatur, Bd. 3, S. $241 \mathrm{ff}$.

171 Morsey, Untergang, S. 24 und $51 \mathrm{ff}$.

172 Ebenda, S. 50. 
lichen Interessen zustandezubringen ${ }^{173}$. Daß die Fraktion zu einem „undisziplinierten Haufen ohne Führung" hatte werden können, lag aber auch an der von Schauff beklagten Entfremdung zwischen Brüning und Kaas, die allerdings erst im Zusammenhang mit dem Ermächtigungsgesetz zu offenem Dissens wurde ${ }^{174}$.

Schauffs auch hinsichtlich seiner eigenen "Mitwirkung bei der Liquidation" der Partei polemisch geäußerte Meinung, das Zentrum sei „irgendwie reif zum Untergang " gewesen ${ }^{175}$, bedarf indes eines kurzen begründenden Exkurses. In der Weimarer Republik hatte die ursprünglich im katholischen Sozialmilieu wurzelnde sowie einer religiösen Wertordnung verpflichtete Partei die traditionelle kulturpolitische Einigungsformel des politischen Katholizismus in Anbetracht der nunmehr verfassungsmäßig garantierten staatsbürgerlichen und kirchenpolitischen Freiheitsrechte weitgehend eingebüßt. Gleichwohl war dem Zentrum im Rahmen des neuen politisch-weltanschaulichen und sozialen Pluralismus eine Schlüsselrolle zugefallen. „Im Weimarer Verfassungssystem“ - so Morsey - „war das Zentrum in die Rolle einer staatstragenden und -stabilisierenden Mittelpartei und damit in eine parlamentarische Schlüssel- und Scharnierstellung hineingewachsen. Die Reichstagsfraktion des Zentrums bildete den eigentlichen Stabilisierungsfaktor für die rasch wechselnden und politisch heterogenen Koalitionsregierungen." ${ }^{176}$ Allerdings hatte die seit Beendigung des Kulturkampfes und verstärkt im Weimarer Staat zunehmende Laizität einen langsamen Abwärtstrend der Wahlerfolge, verbunden mit einer Stagnation der Wählerschaft, verursacht - eine Entwicklung, die durch das Verhältniswahlrecht und die Wahlkreiseinteilungen noch verstärkt wurde. Johannes Schauff hatte in seinen schon angeführten Studien bereits auf diese Entwicklung hingewiesen ${ }^{177}$.

Die strukturelle Krise der Weimarer Republik, bedingt vor allem durch die politische und wirtschaftliche Hypothek des verlorenen Kriegs und des Versailler Vertrags, die zwischen 1919 und 1930 eine Regierung im Schnitt nicht länger als acht Monate im Amt ließ, hatte Brüning nach seinem Amtsantritt im März 1930 zu überwinden versucht. Sein sittlich-moralischer Imperativ und sein nationalkonservatives Dienst- und Staatsethos mochte zwar dem von ihm verehrten Reichspräsidenten imponieren, für dessen Wiederwahl im Frühjahr 1932 Brüning sich persönlich einsetzte, genügte jedoch nicht zu einer Reform der eigenen Partei an Haupt und Gliedern, der Wandlung zu einer christlich-demokratischen Volkspartei, die in der Lage gewesen wäre, den totalitären Bedrohungen von links und rechts zu begegnen. Es galt, den Versuch zu wagen, einen Umsturz zu verhindern, "und zwar durch Revision der parlamentarischen Substanz der Verfassungsordnung zum, wahren' und verantwortungsbewußten Parlamentarismus, ergänzt um eine ,Volkssammlung', einem , auf Zeit begrenzten Zweckhandeln'. Dabei sollte

173 Schauff, Aus meiner beruflichen und politischen Arbeit, S. 7; Morsey, Untergang, S. $30 \mathrm{ff}$.

174 Ebenda, S. $47 \mathrm{ff}$.

175 Schauff, Aus meiner beruflichen und politischen Arbeit, S. 7.

176 Morsey, Untergang, S. 16. 1919 bis 1930 war das Zentrum in 16 unterschiedlich zusammengesetzten Koalitionsregierungen vertreten.

177 Schauff, Wahlverhalten; Tabelle über Stimmen- und Mandatsanteile auch bei Morsey, Untergang, S. $14 \mathrm{f}$. 
die ,bloße Formaldemokratie' und der ,ungesunde', funktionsunfähig gewordene Parlamentarismus überwunden und einer von den Parteien unabhängige Regierung die Möglichkeit kontinuierlicher Arbeit gegeben werden. " 178

Die avisierte „Volkssammlung“ bedeutete 1932/33 zunächst den Versuch einer parlamentarischen Mehrheitsbildung unter Einschluß sowohl der Deutschnationalen als auch von gemäßigt geltenden Teilen der Nationalsozialisten. Indessen gelang es Brüning nicht, diese politischen Kräfte in Koalitionen einzubinden und damit vielleicht zu neutralisieren, ein Bemühen, das auch in Kontrast stand zu der in Preußen weiterbestehenden „Weimarer Koalition" mit den Sozialdemokraten. Deren kulturpolitischer Kurs wurde allerdings mitverantwortlich gemacht für den fortschreitenden Säkularisierungsprozeß, dessen Folgen auch im Vatikan kritisch wahrgenommen wurden, was Brüning und Wirth anläßlich von Besuchen in Rom im Jahr 1931 aufmerksam registrierten. Das Kabinett Brüning wurde schließlich am 30. Mai 1932 gestürzt - einer der Gründe war der Vertrauensentzug durch den Reichspräsidenten, für dessen Wiederwahl im Frühjahr 1932 der Kanzler sich noch wie ein treuer Ekkehard eingesetzt hatte. Statt einer nationalen Sammlungsbewegung zur Bildung regierungsfähiger parlamentarischer Mehrheiten kam es zu den Präsidialkabinetten Papen und Schleicher, bei deren Bekämpfung das Zentrum wiederum nicht auf die Unterstützung der Nationalsozialisten glaubte verzichten zu können. Der Kampf galt vor allem dem „abtrünnigen“ Papen, dessen „Preußenschlag“, d.h. die staatsstreichartige Beseitigung der preuBischen Landesregierung am 20. Juli 1932, den Dissens noch verschärft hatte. Wie Schauff vermerkte, wurden die Koalitionsbemühungen und -verhandlungen der Zentrumsführung mit der NSDAP von den Parteianhängern und der Fraktion keineswegs positiv aufgenommen. Schließlich hatte die Partei beim Reichspräsidenten gegen die terroristischen Wahlkampfmethoden der Nationalsozialisten protestiert ${ }^{179}$, und es war vielen Abgeordneten bewußt, daß die "neuheidnische“ Ideologie des Nationalsozialismus von höchster kirchlicher Warte abgelehnt wurde ${ }^{180}$.

Im letzten Reichstagswahlkampf im Februar/März 1933 war der Hauptgegner der Partei weniger Hitler als Hugenberg. Die Verhandlungsführer Kaas und Perlitius, aber auch die übrigen Parteiführer besaßen, wie Schauff anmerkt, kaum ein "Gespür" für das "Totalitär-Dämonische“ der neuen Machthaber ${ }^{181}$. Die fatale Unterschätzung der nationalsozialistischen Bewegung führte schließlich zur Zustimmung zum sogenannten Ermächtigungsgesetz. Nach der nationalsozialistischen Machtübernahme und vor allem im Vorfeld der angesetzten Neuwahlen hatte das Zentrum als „Systempartei“ gleichwohl bald die ersten Repressionsmaßnahmen erfahren, waren die Presse unterdrückt und nach dem Reichstagsbrand am 27. Februar 1933 die ersten einschneidenden Notverordnungen

178 Ebenda, S. 23.

179 Vgl. Das Zentrum 3 (1932), S. 206; Morsey, Untergang, S. 53.

180 Vgl. Wahlhirtenbrief der Fuldaer Bischofskonferenz vom 12. Juli 1932; Morsey, Untergang, S. 22, 51.

181 Schauff, Aus meiner beruflichen und politischen Arbeit, S. 6 f; Morsey, Untergang, S. $88 \mathrm{ff}$. 
erlassen worden. Am 9. März wurde der oberschlesische Zentrumspolitiker Prälat Ulitzka, dem Schauff aus der Zeit seiner schlesischen Wahlkämpfe freundschaftlich verbunden war, von der SA mißhandelt und in Schutzhaft genommen ${ }^{182}$. Ein anderer Aspekt, der auch Schauff direkt betraf, war die Verdrängung von Zentrumspolitikern aus ihren Stellungen im öffentlichen Leben und im Öffentlichen Dienst ${ }^{183}$.

Bereits mit der Auflösung des Reichstags war vom Kabinett beschlossen worden, dem neuen Parlament ein Ermächtigungsgesetz vorzulegen, ein Vorgang, mit dem Hitler einen Schlußpunkt hinter die Verhandlungen mit den allzu gutgläubigen Zentrumsvertretern gesetzt hatte ${ }^{184}$. Auch die späteren Bemühungen, auf die inhaltliche Formulierung des Ermächtigungsgesetzes Einfluß zu nehmen, scheiterten: Am 20. März hatten Kaas und Stegerwald mit Hitler und Frick verhandelt, später hatte Brüning sich sogar bemüht, mit dem bis dahin befehdeten Hugenberg in der Sache ein Zweckbündnis zu schließen ${ }^{185}$. Auch diese Verhandlungen waren, wie Schauff kritisierte, ohne Hinzuziehung der Fraktion geführt worden. Gleichwohl war eine Mehrheit der Abgeordneten grundsätzlich bereit, dem Ermächtigungsgesetz zuzustimmen; neben einem gewissen Verständnis für die von nationalsozialistischer Seite angeführte politische Begründung für einen solchen Eingriff dürfte hierbei der zunehmende terroristische Druck der SA auf den Straßen wie innerhalb des Parlaments nicht ohne Einfluß gewesen sein. Beratungen innerhalb der Fraktion bzw. eine offene Aussprache waren zu diesem Zeitpunkt kaum noch möglich; hinzu kam, daß der entsprechende Gesetzentwurf entgegen der Zusage Hitlers der Fraktion nicht übermittelt worden war.

Die Bereitschaft, positiv auf die Gesetzesvorlage zu reagieren, war innerhalb der Fraktion vor allem von Hackelsberger ${ }^{186}$ gefördert worden, aber auch Kaas, der nach Schauff „der Fraktion die Zustimmung mit überklugen Argumenten schmackhaft zu machen" bemüht war, spielte eine zweideutige Rolle ${ }^{187}$. Obwohl die taktisch geschickten Ausführungen des Reichskanzlers Hitler zu dem Gesetz in der Reichstagssitzung vom 23. März 1933 die Mehrheit der Zentrumsabgeord-

182 Gerhard Webersinn, Prälat Carl Ulitzka, in: Jahrbuch der Schlesischen Friedrich-Wilhelm-Universität zu Breslau 15 (1970), S. 191; Hitze, Die Zentrumspartei, S. 175 f.

183 Diese Verdrängung sollte später für das Wiedergutmachungsverfahren Schauffs in der deutschen Bundesrepublik eine Rolle spielen. Allerdings war die GFK urprünglich eine Gesellschaft bürgerlichen Rechts und später ein eingetragener Verein (Boyens, Siedlung, Bd. I, S. III und 77 ff.); vgl. den Wiedergutmachungsbescheid Johannes Schauff vom 26. Juni 1959, IfZ, NL Schauff, Bd. 27; zu dem Vorgang der Wiedergutmachung siehe unten, S. $136 \mathrm{f}$.; Morsey, Untergang, S. $105 \mathrm{f}$.

184 Ebenda, S. 92.

185 Ebenda, S. $126 \mathrm{ff}$.

186 Albert Hackelsberger (1893-1940), MdR 1932-33, anschließend bis 1938 (Ausschluß) Gaststatus in der NSDAP-Fraktion; 1938 Verfahren wegen Volksverrat und bis 1940 in Haft.

187 So heißt es in einer „Eidesstattlichen Erklärung“ des sozialdemokratischen Politikers und früheren Reichstagsabgeordneten Heinrich Ritzel vom 30. August 1961, daß ihn Kaas zu einem positiven Votum gedrängt habe: „Herr Ritzel, Sie haben Frau und drei Kinder; ich beschwöre Sie, stimmen sie dem Ermächtigungsgesetz zu“ (IfZ, NL Schauff, Bd. 24); vgl. auch Morsey, Untergang, S. 256, Anm. 6. 
neten schließlich zu beruhigen vermochten, war eine Minderheit unter Brüning entschlossen, mit „Nein“ zu votieren. Daraufhin setzte Kaas in der Sitzungspause eine Probeabstimmung an. Unterlagen oder Stimmzettel zu dieser Abstimmung sind nicht mehr vorhanden. Nach Schauffs Aufzeichnungen vom Dezember 1934 gehörten zu der dissidenten Gruppe 15 von insgesamt 72 Abgeordneten ${ }^{188}$. Darunter fanden sich Heinrich Brüning und führende Zentrumspolitiker wie Joos und Wirth sowie andere prominente Abgeordnete wie Bolz, Bockius, Dessauer, Ersing, Fahrenbrach, Imbusch, Christine Teusch und Helene Weber ${ }^{189}$ sowie jüngere bzw. neu gewählte Zentrums-Parlamentarier - neben Schauff Hermann Joseph Schmitt 190 und Jakob Kaiser.

Für den weiteren Fortgang der Dinge blieb der Vorgang dieser Probeabstimmung jedoch ohne Konsequenzen. Auf Kaas' Drängen hin beschloß die Fraktion, mit Rücksicht auf das Schicksal der Partei ein „entpersönlichtes“ Votum abzugeben und, der Mehrheit folgend, geschlossen für das Ermächtigungsgesetz zu stimmen. In der am Nachmittag weitergeführten Sitzung votierten schließlich die 72 Zentrums-Abgeordneten, darunter auch Schauff, ohne Ausnahme mit Ja ${ }^{191}$.

Ausschlaggebend für diese Entscheidung war einerseits wohl das Bemühen, bei der von Hitler propagierten "nationalen Sammlung" politisch nicht abseits zu stehen, zum andern brachte die Zustimmung zum Ermächtigungsgesetz für das Zentrum scheinbar durchaus inhaltliche Vorteile wie z.B. die Sicherung der katholischen Schulerziehung und die Respektierung der Länderkonkordate - Hitler hatte in seiner Reichstagsrede ausdrücklich auf die guten Beziehungen zum Heiligen Stuhl hingewiesen, die es auszugestalten gelte. Darüber hinaus mag Furcht die Entscheidungsfindung der Abgeordneten beeinflußt haben, stand doch das Schicksal der Sozialdemokraten und Kommunisten in den Konzentrationslagern vielen warnend vor Augen. Doch blieb die Fraktion letztlich der Gefangene des eigenen Zähmungs- und Tolerierungskonzepts gegenüber den Nationalsozialisten sowie der eigenen Sammlungsparole ${ }^{192}$. Für viele Zentrums-Parlamentarier bedeutete die Entscheidung für das Ermächtigungsgesetz eine schwere Hypothek, die noch lange nachwirkte; $z$ wischen Brüning und Kaas bewirkte sie eine nachhaltige und tiefe Entfremdung.

Die nunmehr „legalisierte“ politische Entwicklung schritt allerdings rasch über das Zentrum hinweg. Nachdem Kaas am 7. April nach Rom abgereist und Wirth

188 Morsey hat recherchiert, daß es sich wohl um 12 bis 14 Abgeordnete gehandelt habe (Morsey, Untergang, S. 140).

189 Von den genannten Zentrumsabgeordenten wurden Fritz Bockius und Eugen Bolz noch 1945 im Konzentrationslager Mauthausen (Bockius) und in Plötzensee (Bolz) ermordet; Josef Joos (ab 1940), Heinrich Fahrenbrach (1944) und Joseph Ersing (1944) waren in Konzentrationslager- und Gefängnishaft; Helene Weber und Christine Teusch wurden mit Berufsverbot belegt und von der Gestapo schikaniert; Heinrich Brüning, Joseph Wirth, Friedrich Dessauer und Heinrich Imbusch gingen in die Emigration. Alle Biographien in M.d.R. Die Reichstagsabgeordneten der Weimarer Republik in der Zeit des Nationalsozialismus, sowie in BHB I.

190 Zur Biographie Hermann Joseph Schmitt siehe S. 55, Anm. 165.

191 Bei der Abstimmung fehlte der Zentrumsabgeordnete Karl Diez. Morsey, Untergang, S. 143.

192 Ebenda, S. 162. 
bereits am 24. März emigriert war ${ }^{193}$, geriet die Partei in eine Phase vollständiger Führungslosigkeit, bis am 7. Mai Heinrich Brüning zum neuen Parteivorsitzenden gewählt wurde. Die danach erfolgte geradezu kultische Hinwendung zum Führerprinzip und die in Angriff genommenen Reorganisationspläne, bei denen vor allem junge Kräfte wie Schauff eingesetzt werden sollten, konnten den beschleunigten Niedergang der Partei dennoch nicht aufhalten. Auch Brüning war um Vorleistungen gegenüber dem nationalsozialistischen Regime bemüht, wenn es sich um den Appell an nationale Gemeinsamkeiten handelte - so zuletzt anläßlich Hitlers außenpolitischer Regierungserklärung auf der Reichstagssitzung vom 17. Mai 1933. Dieses nachgiebige Verhalten erschien den Gegnern jedoch als ein Zeichen der Schwäche, die sie zu sich steigernden Angriffen auf den politischen Katholizismus nutzten. Zu gleicher Zeit wurde bekannt, daß Kaas in Rom an Konkordatsverhandlungen mit dem Vatikan beteiligt war. Ein an Brüning übersandter Entwurf wurde von diesem als ungenügend abgelehnt, die an der Partei vorbei geführten Verhandlungen offenbarten zugleich deren politisches Abseits und trugen damit zur steigenden Resignation des Vorsitzenden bei. Das Bemühen einer kleinen Gruppe von jüngeren Abgeordneten - darunter Johannes Schauff und Bernhard Letterhaus - angesichts des sich abzeichnenden Niedergangs ein „anständiges Sterben“ des Zentrums in die Wege zu leiten, blieb erfolglos ${ }^{194}$.

In der zweiten Junihälfte 1933 begannen Regierung und NSDAP, mit terroristischen Maßnahmen die Zentrumspartei zu zerschlagen; eine Reihe ihrer Abgeordneten wurde verhaftet ${ }^{195}$. Nachdem am 22. Juni das Verbot der SPD erfolgt war, wurden im Zuge der Gleichschaltungsmaßnahmen zahlreiche katholische Organisationen aufgelöst, darunter die Windthorstbunde; der Volksverein für das katholische Deutschland löste sich selbst auf. Auch die bevorstehende Paraphierung des Reichskonkordats (8. Juli 1933) verhalf dem Zentrum nicht aus seinem politischen Dilemma, vielmehr konnte Hitler nunmehr die von ihm propagierte positive Regelung der Beziehungen zur katholischen Kirche als Erfolg verbuchen, zu dem er die Zentrumspartei nicht mehr benötigte ${ }^{196}$.

Die Selbstauflösung des Zentrums wurde vor allem von Hackelsberger betrieben, der zugleich mit Innenminister Frick verhandelte, um Zentrumsabgeordnete als Hospitanten in die Reichstagsfraktion der NSDAP zu übernehmen. Am 5. Juli 1933 schließlich wurde nach letzten Gesprächen zwischen Brüning, Joos, Hakkelsberger und Wegmann die Selbstauflösung des Zentrums bekanntgegeben ${ }^{197}$. In dem alsbald gegründeten „Kuratorium für das Restvermögen“ der Partei, das

193 Wirth war am 24. März 1933 in die Schweiz emigriert, BHB I; zu Kaas' Emigration und ihrer Motivation vgl. Georg May, Ludwig Kaas, Bd. 3, S. 371 ff.; zur Emigration von Kaas und Wirth (und Brüning) vgl. Morsey, Leben und Überleben um Exil, S. 86-117.

194 Morsey, Untergang, S. 191.

195 Am 19. Juni 1933 war Eugen Bolz verhaftet und mißhandelt worden, später auch der württembergische Reichstagsabgeordnete und Gewerkschaftsführer Josef Ersing; Helene Weber wurde als Ministerialrätin im preußischen Kultusministerium entlassen.

196 Allgemein zum Reichskonkordat von 1933: Volk, Das Reichskonkordat; Morsey, Untergang, S. $202 \mathrm{f}$.

197 Der in der Presse veröffentlichte Auflösungsbeschluß abgedruckt in: Morsey, Die Deutsche Zentrumspartei, S. $439 \mathrm{f}$. 
die finanzielle Gesamtabwicklung regeln sollte, übernahm Schauff eine letzte Aufgabe ${ }^{198}$. Er figuriert auch auf einer weiteren Hospitantenliste für die NSDAP, die Hackelsberger am 19. Oktober 1933 Frick vorlegte und die 27 Namen umfaßte ${ }^{199}$. Akzeptiert wurden schließlich lediglich Hackelsberger und der württembergische Gutsbesitzer Oskar Farny. „Ich war anwesend“, erinnert sich Schauff, „als Domkapitular Lenné/Köln bei Dr. Hackelsberger in Berlin im Auftrag des Kölner und des Breslauer Kardinals intervenierte ${ }^{200}$, damit möglichst viele katholische Abgeordnete übernommen würden. Hackelsberger hat aber eine Vorschlagsliste abgegeben, die ausgesprochene Nazigegner enthielt und sie dadurch zum Scheitern gebracht. Er selbst wurde übernommen sowie Dr. Farny ... Als politischer Vertrauensmann von Erzbischof Gröber/Freiburg hielt Hackelsberger engen Kontakt mit Kaas im Vatikan. Ich traf ihn mehrfach in Rom, voller Sorge und Skepsis über die Haltbarkeit des Konkordats."201 Rom war zu dieser Zeit für die Familie Schauff bereits die erste Station ihres Weges in die Emigration. Doch räumte Johannes Schauff keineswegs völlig kampflos das Feld.

198 Dem Kuratorium, das sich am 18. Oktober 1933 wieder auflöste, gehörten neben Schauff Heinrich Krone, Hackelsberger, Gerig, Wegmann und Landgerichtsdirektor Cremer an. Morsey, Untergang, S. 211.

199 Neben Schauff und Hackelsberger selbst befinden sich auf dieser Liste die weiteren $\mathrm{Na}$ men Krone, Fonk, Wegmann und Vockel, vgl. Morsey, Untergang, S. 212, Anm. 19.

200 Kardinal Karl Joseph Schulte (Köln) und Kardinal Adolf Bertram (Breslau).

201 Schauff, „Wer von den Zentrumsabgeordneten wurde in die nationalsozialistische Fraktion als Hospitant und später auf die Einheitsliste der NSDAP übernommen und gewählt?“ (Ms. [Entwurf], IfZ, NL Schauff, Bd. 24). 